\title{
A comprehensive glycome profiling of Huntington's disease transgenic mice
}

Solomon T. Gizaw ${ }^{\mathrm{a}}$, Toshiaki Koda ${ }^{\mathrm{b}}$, Maho Amano ${ }^{\mathrm{a}}$, Keiko Kamimura ${ }^{\mathrm{b}}$, Tetsu Ohashi ${ }^{\mathrm{a}, \mathrm{c}}$, Hiroshi Hinou $^{\mathrm{a}, \mathrm{c}}$, Shin-Ichiro Nishimura ${ }^{\mathrm{a}, \mathrm{c}, *}$

${ }^{[a]}$ Field of Drug Discovery Research, Faculty of Advanced Life Science, and Graduate School of Life Science, Hokkaido University, N21 W11, Sapporo, 001-0021, Japan

${ }^{[b]}$ Laboratory of Embryonic and Genetic Engineering, Faculty of Advanced Life Science, Hokkaido University, N21 W11, Sapporo 001-0021, Japan

${ }^{[c]}$ Medicinal Chemistry Pharmaceuticals, Co.Ltd, N21 W12, Sapporo 001-0021, Japan

${ }^{*}$ To whom correspondence should be addressed

E-mail: shin@sci.hokudai.ac.jp

Phone: +81-11-706-9043

Fax: +81-11-706-9042 


\begin{abstract}
Background: Huntington's disease (HD) is an autosomal, dominantly inherited and progressive neurodegenerative disease, nosologically classified as the presence of intranuclear inclusion bodies and the loss of GABA-containing neurons in the neostriatum and subsequently in cerebellar cortex. Abnormal processing of neuronal proteins can result in the misfolding of proteins and altered post-translational modification of newly synthesized proteins. Total glycomics, namely, $\mathrm{N}$-glycomics, $\mathrm{O}$-glycomics, and glycosphingolipidomics (GSL-omics) of HD transgenic mice would be a hallmark for central nervous system disorders in order to discover disease specific biomarkers.
\end{abstract}

Methods: Glycoblotting method, a high throughput glycomic protocol, and matrix-assisted laser desorption ionization-time of flight/mass spectrometry (MALDI-TOF/MS) were used to study the total glycome expression levels in the brain tissue (3 mice of each sex) and sera (5 mice of each sex) of HD transgenic and control mice. All experiments were performed twice and differences in the expression levels of major glycoforms were compared between HD transgenic and control mice.

Results: We estimated the structure and expression levels of 87 and $58 \mathrm{~N}$-glycans in brain tissue and sera, respectively, of HD transgenic and control mice. The present results clearly indicated that the brain glycome and their expression levels are significantly gender specific when compared with those of other tissues and serum. Core-fucosylated and bisecting-GlcNAc types of $\mathrm{N}$-glycans were found in increased levels in the brain tissue HD transgenic mice. Accordingly, core-fucosylated and sialic acid (particularly $N$-glycolylneuraminic acid, NeuGc) for biantennary type glycans were found in increased amounts in the sera of HD transgenic mice compared to 
that of control mice. Core 3 type $O$-glycans were found in increased levels in male and in decreased levels in both the striatum and cortexes of female HD transgenic mice. Furthermore, serum levels of core 1 type $O$-glycans decreased and were undetected for core 2 type $O$-glycans for HD transgenic mice. In glycosphingolipids, GD1a in brain tissue and GM2-NeuGc serum levels were found to have increased and decreased, respectively, in HD transgenic mice compared to those of the control group mice.

Conclusion: Total glycome expression levels are significantly different between HD transgenic and control group mice.

General significance: Glycoblotting combined with MALDI-TOF/MS total glycomics warrants a comprehensive, effective, novel and versatile technique for qualitative and quantitative analysis of total glycome expression levels. Furthermore, glycome-focused studies of both environmentally and genetically rooted neurodegenerative diseases are promising candidates for the discovery of potential disease glyco-biomarkers in the post-genome era.

Key words: Huntington's disease, Total glycomics, Transgenic mouse, Glycoblotting, Glycobiomarker

\section{Abbreviations}

HD, Huntington's disease; CDG, congenital disorders of glycosylation; CNS, central nervous system;GSL-omics,glycosphingolipidomics; PolyQ, polyglutamine;TCEP, Tris (2-carboxyethyl) phosphine hydrochloride; MeOH, methanol; ConA, Canavalia ensiformis; LCA, Lens culinaris; PHA-E 4 , Phaseolus vulgaris; DSA, Datura stramonium; SSA, Sambucus sieboldiana; PNA, Arachis hypogaea; PAS, Periodic Acid-Schiff;MTT, 3-methyl-1-p-tolyltriazene; DTT, 
dithiothreitol;PB, phosphate buffer;PBS, phosphate buffer saline;MALDI-TOF/MS, matrixassisted laser desorption ionization-time of flight/mass spectrometry.

\section{Introduction}

Huntington's disease (HD), oneof the trinucleate repeate disorders, is nosologically classified as the presence of neuronal intranuclear inclusions (NIIs), dystrophic neuritis (DNs) and the loss of GABA-containing neurons in the neostriatum and, subsequently, in the cerebellar cortex [1]. The HD mutation is dominant and almost completely penetrate [2]. The increased numbers of CAG repeats in the HD gene are expressed as an elongated huntingtin (HTT) protein with 40 to 150 polyglutamine (polyQ) residues (CAG ranges for normal individuals are 9-35). The huntingtin, the function of which is unknown, is a $350 \mathrm{KDa}$ protein encoded by the HD gene (initially labeled as IT15)[1-4]. It is associated with proteinaceous deposits that are found in patients' brain of which aggregated polyQ is a major component [5]. The disease is caused by an abnormal elongation of a CAG repeat sequence in exon 1 of the HD gene [6], which is sufficient to cause a progressive neurological phenotype in transgenic mice [7]. HD is an autosomal, dominantly inherited, and progressive neurodegenerative disorder and, accordingly, the hallmark for fatal genetic diseases [8-12].

The atrophy of the neurons due to pediatric and adulthood diseases of the central nervous system leads to aberrant glycosylation and the biosynthesis pattern of the available glycans is altered. Aberrant glycosylation, in turn, impairs neurite growth and fasiculation, synapse formation and stabilization, and also causes psychomotor difficulties, mental retardation and other neuropathological symptoms that are highlighted by congenital disorders of glycosylation (CDG) [13]. Understanding the glycosylation pattern of $\mathrm{N}-, \mathrm{O}-$, and glycosphingolipids (GSL)-glycans, which is affected by either genetic or environmental cellular stressors, is a promising step 
towards an easy prognosis of disease progression. Either serum or cerebrospinal fluids (CSF) specimens from human with neurodegenerative and aging are validated for biomarker detection [13-15]. Glycosylation is the most prevalent post-translational modifications (PTM) of proteins in higher organisms essential to modulate a wide range of protein and lipid functions within or on extracellular surfaces of the cell. Protein glycosylation is either $N$-linked (GlcNAcß-Asn) linkage with a minimal amino acid sequence of Asn-X-Ser/Thr, where $\mathrm{X} \neq$ Pro) or $O$-linked (where GalNAc is added to Ser or Thr), and GSLs are synthesized by a sequential transfer of sugar residues to a ceramide lipid anchor. Interestingly, all share pivotal roles such as cellular differentiation, adhesion, immunity, signal transduction and growth control [16-18]. However, there is no comprehensive glycomics focusing on mammalian brain glycoconjugates towards the discovery of neurodegenerative biomarkers while a few $\mathrm{N}$ - and $\mathrm{O}$-glycans specific to rat brain glycoproteins have been reported [19-21].

Glycomics is the systems-level study of the glycan repertoires (glycomes), which comprise the entire set of glycans produced in a single organism [22]. It has been an attractive area of research in the postgenome era emerging as a new paradigm for biomarker discovery [23-27]. However, the stereochemical and structural diversity of monosaccharides, the heterogeneous or highly complicated glycan structures of glycoproteins (microheterogeneity), the multivalent nature of glycan-protein interactions [27,28], and the lack of a direct genetic code for glycan complex modification (the non-tempelate dependent biosynthesis of glycans) [29-31] are the challenges that scientists are faced with. As the most structurally and functionally diverse class of molecules in nature to undergo versatile protein modifications, glycoconjuagtes play a role in tracing the cellular glycosylation patterns of multifunctional proteins [32] as well as finding potential biomarkers in the field of drug discovery [33,34]. 
Many efforts to identify glycosylation defects in cases of CDG. These include the study of conserved oligomeric Golgi (COG)-deficient patients and the increasing prevailence age and age-related diseases identified via glycoform characterization of serum, plasma and CSF by using ESI-MS, affinity chromatography, and 2-DE followed by MS/MALDI-MS/DNA sequencer adapted-fluorophore assisted carbohydrate electrophoresis (DSA-FACE) and HILICHPLC [13]. Moreover, glycosylation changes in non-invasive bodily fluids, inter alia, serum, urine, plasma glycomes and on individual glycoproteins have been identified as promising biomarkers for the detection of prostate cancer [28], hepatocarcinoma cancer (HCC) and cirrhosisof the liver [35,36], pancreatic cancer [37], ulcerative colitis [38], and bladder cancer [39]. Measuring the degree of alteration of specific glycans in serum/plasma or whole blood has helped to provide a novel, non-invasive method for determining prognose in cases of cancer and the existence of specific altered glyco-phenotypes, which might represent risk factors for the sequela of certain diseases [40-44]. Huntingtin protein targeting experiments have also been performed to understand the pathogenesis of $\operatorname{HD}[2,6]$. Since oliogosaccharides attached to the proteins play significant roles in tissue development and maintenance, the brain tissue of HD transgenic mice providesadditionalsystemsfor such studies [6,19]. As a first initiative, we have estimated the glycan composition and quantified the total glycomes ( $\mathrm{N}-, \mathrm{O}-$, and GSL-glycans) expressed in 12 weeks-old HD transgenic and WT mice via glycoblotting [45-47] assisted sample preparation, i.e., glycan enrichment, combined with MALDI-TOF/MS analysis.

Glycoblotting [45-47] is a standardizable technology in high throughput glycomics. It was developed in our laboratory to facilitate the glycan enrichment process of highly complicated mixtures such as bodily fluids, cells, tissues, and organs of both human and knock-out mice.The purpose of this enrichment process was to assess changes in the $N-, \mathrm{O}-$, GSL-glycans expression 
levels of PTMs in various human diseases when compared with those of normal controls. This new operational method has been applied to large scale structural and functional analysis of protein glycosylation [48-51], diseases related to glycan biomarker exploration [36-39,52], and to reveal the trends and complex patterns of glycans in diverse taxonomic groups of different bird species [53]. It seems likely that MS-based glycome analysis is one of the rapid and sensitive methods to carry out large-scale analyses for the discovery of disease-relevant biomarkers [54]. Achievements stemming from a multitude of samples studies have encouraged us to extend our efforts to estimate the structural composition and total glycome expression levels in HD via glycoblotting-assisted MALDI-TOF/MS analysis and avidin-biotin complex lectin staining [55]. We were able to observe a difference in structure and in the amount of glycomes between HD transgenic and control group mice. As a touchstone of the neurodegenerative disease, total glycomics of HD can serve a blueprint to profile the glycomes of either environmentally or genetically based CNS disorders viz., Alzheimer’s, and Parkinson's disease, spinocerebellar ataxia, and amyotrophic lateral sclerosis. Such an achievement would be a great step towards the discovery of new glyco-biomarkers for this particular class of diseases. 


\section{Material and Methods}

\subsection{Animal}

Animal experiments were conducted under the guidelines and with the approval of the committee on animal experiments of Hokkaido University. B6CBA-Tg (HDexon1) 62Gpb/1J, aka R6/2, transgenic mice expressing the $N$-terminal region of a mutant human huntingtin gene [7] were purchased from Jackson Laboratory. R6/2 mice were bred by ovarian transplantation to B6CBAF1 (BCF1) mice by mating with a BCF1 male. The length of the trinucleotide repeat was monitored by PCR amplification and gel electrophoresis of the tail DNA of the offspring, and was determined to contain 120-150 repeats. Mice were group housed in individually ventilated shoebox cages with paper bedding and a filter top. Food and water were available ad libitum. The neurological phenotypes of the R6/2 mice appeared between 6-9 weeks of age and the mice died at 14-18 weeks. Even though the phenotype is very complex, there are a number of components of the motor disorders. These include resting tremors, movements resembling chorea, stereotypic involuntary movements, mild ataxia, dyskinesia of the limbs. As the disease progresses mice are frequently observed to eat without gaining weight or, in more severe cases, emaciated with an overall loss of muscle bulk [7]. In this study, we used 3 mice of each sex (HD transgenic and control mice) for brain tissues glycome analysis, 5 mice of each sex (HD transgenic and control mice) for serum glycome analysis and all experiments were performed twice.

\subsection{Reagents and equipments}

TCEP, trypsin, PAS kit, Mayer’s heamatoxylin, DTT, ConA- and SSA-biotin conjugated lectins were purchased from Sigma-Aldrich. PNGase F was purchased from New England Biolabs ${ }^{\circledR}$ Inc. 
(Ipswich, Massachusettes, USA). Ammonium carbamate (99\%) and 1-propansulfonic acid-2hydroxyl-3-myristamido (PHM) were obtained from Tokyo Kasei (Chuo-ku, Tokyo, Japan). Chitooligosaccharide mixture was from Seikagaku Biobusiness (Tokyo, Japan). BlotGlyco ${ }^{\circledR} \mathrm{H}$ beadwas purchased from Sumitomo Bakelite (Tokyo, Japan). MTT, O-benzylhydroxylamine hydrochloride (BOA) and disialylated biantennary oligosaccharide (A2; (Hex) $)_{2}(\mathrm{HexNAc})_{2}$ $\left.(\mathrm{NeuAc})_{2}+(\mathrm{Man})_{3}(\mathrm{GlcNAc})_{2}\right)$ were purchased from Tokyo Chemical Industry Co., Ltd. Somnopentyl ${ }^{\circledR}$ (Pentobarbital sodium) and Agarose LO3 were purchased from Kyoritsu Seiyaku (Tokyo) and Takara Bio, Inc (Otsu), respectively, of Japan. DSA-, LCA-, PHA-E $4^{-}$, and PNAbiotin-conjugated lectins were from J-OIL MILLS, Inc (Chuo-ku, Tokyo, Japan). VECTASTAIN $^{\circledR}$ Elite ABC and ImmPACT DAB (3, 3-diaminobenzidine tetrahydrochloride) Peroxidase SubstrateKitswere from Vector Laboratories (Burlingame, CA, USA). Immunopen, other reagents and solvents were obtained from Wako Pure Chemicals (Tokyo, Japan) and Kanto Chemical Co., Inc., unless otherwise stated.

MultiScreen Solvinert filter plates and Mass PREPTM HILIC $\mu$ Elution plates were purchased from Millipore and Waters, respectively.The ozone generator used (NG81-NO3, T-153) was from Nigorikawakogyo, Japan. Slicer VT1000S was obtained from Leica Microsystems Co. Ltd. Our fluorescence digital microscope (BA210EINT) was obtained from Shimadzu (Tokyo, Japan), and the automated glycan-processing machine (Sweetblot) was obtained from Systems Instruments Corporation (SIC). All mass measurements were performed using MALDI-TOF/MS (Ultraflex III, Bruker Daltonics, Germany).

\subsection{Perfusion of mice}


For lectin staining, each mouse was injected intraperitoneally with $0.1 \mathrm{~mL}$ Somnopentyl ${ }^{\circledR}$ for using a $26 G^{1} / 2$ inch needle. The mice were subsequently observed until they fell asleep to avoid vasoconstriction reflex and ensure that the each mouse survived. Each mouse was fixed on the surgical table with a plastic vat and the abdominal skin was cut with scissors and stripped. The abdominal wall, diaphragm, and costal bone were cut to expose the heart. After the peristaltic pump was switched on anda steady flowwas confirmed, the right atrial appendage was cut and the needle was quickly inserted into the left ventricle. Perfusion was performed for 10 mins with a fixing solution (4\% paraformaldehyde in $0.1 \mathrm{M}$ phosphate buffer, $\mathrm{PB}$ ) by a peristaltic pump adjusted to a flow rate of $10 \mathrm{~mL} / \mathrm{min}$, until the internal thoracic artery and liver were whitish incolor, and the body became rigid. After the neck, head skin and cranial bone were cut, the brain wasremoved, placed in a tube containing a fixing solution and stored at $4{ }^{\circ} \mathrm{C}$. For glycoblotting, perfusion was done with PBS instead of fixing solution. For some experiments using unperfused brain tissues, tissues were recovered from the mice immediately following euthanasationby cervical dislocation. The brain tissues for glycoblotting were stored at $-80^{\circ} \mathrm{C}$ until they were used [55].

\subsection{Embedding, slicing and lectin staining (avidin-biotin complex method)}

The desired portion of the perfused mouse brain tissues (striatum and cortex) were prepared and placed ona glass dish. A 2\% agarose LO3/0.1 M PB was poured onto the brain tissue and the gel was allowed to solidify. Tissue slicing was carried out using a LECIA VT1000S slicer (Speed, 7; Frequency, 6.5; and Feed, $40 \mu \mathrm{M}$ ) after which the sliceswere stored at $4^{\circ} \mathrm{C}$ in a 24 -wells dish containing $0.1 \mathrm{M} \mathrm{PB} / 0.1 \% \mathrm{NaN}_{3}$. The tissue slices were then washed with PBS and air dried. Each slide was marked with an Immunopento minimize the wastage of antibody and to ensure an efficient immunoreaction. Tissue sections were suspended in a $700 \mu \mathrm{L}$ biotin-labeled lectin 
solutions (30 $\mu \mathrm{g} / \mathrm{mL}$, except ConA was $10 \mu \mathrm{g} / \mathrm{mL}$ ) and incubated for $1 \mathrm{hr}$ on ice. Each slice was then washed three times with PBS over a period of 5 mins and was incubated with ABC reagent (700 $\mu \mathrm{L}$, VECASTAIN ${ }^{\circledR}$ EliteABC kit standard) for 30 mins. PBS wash was repeated as described above. The tissue was incubated with ImmPACT DAB peroxidase substrate (700 $\mu \mathrm{L}$ ) for 2 mins followed by washing in two changes of water in 5 min intervals. Following counter staining with Mayer's haematoxyline for one minute, the tissue was washed with tap water for 5 mins. Next, the tissue was dehydrated by passing through 70, 80, 90 and $100 \%$ ethanol and xylene washes, successively and, in 5 mins intervals for each concentration. DAB-labeled slides were mounted in a non-aqueous mounting medium (Entellan New, Merck Millipore, Germany) using a light microscope. Both the striatum and cortex were viewed at 40X, 100X, and 400X [55]. PAS staining was performed based on the manufacture's protocol. Briefly, tissue sections were deparaffinized and hydrated in deionized water. The slides contained tissue sections were immersed in periodic acid solution for 5 mins at room temperature. The slides were rinsed in several changes of distilled water and were immersed in Schiff's reagent for 15 mins at room temperature. After the slides were washed in running tape water for 5 mins, the slides were counter stained in Hematoxylin solution for 90 seconds. The slides were rinsed in running tape water, dehydrated, and cleared. Finally, the slides were mounted in xylene-based mounting medium in a same manner as described above.

\subsection{Mouse serum preparation}

Blood was collected from the heart of 12-week-old mice ( $\mathrm{n}=5$ of each sex of HD transgenic and control mice). Briefly, the mice were restrained and the heart was opened after the abdominal bone, diaphragm, and costal bone were cut. About 400-500 $\mu \mathrm{L}$ of blood was collected using $26 \mathrm{G}^{1 / 2}$ syringes while the heart was beating. The blood was allowed to clot at $4^{\circ} \mathrm{C}$ for 16 hours. 
Then, the clotted blood was centrifuged at 5,000 rpm for 5 mins. The supernatant (serum) was carefully transferred to a new Eppendorf tube and stored at $-80^{\circ} \mathrm{C}$ until the day of use.

\subsection{Releasing $N$-glycans from brain tissue glycoproteins}

Prefused mouse brain tissue ( $\mathrm{n}=3$ of each sex for HD transgenic and control mice), subfragmented into 2-3 mm squares with razor, was homogenized in a lysis buffer (2\% SDS, $5 \mathrm{mM}$ TCEP in $0.1 \mathrm{M}$ Tris-acetate, $\mathrm{pH} 7.4,100 \mathrm{mg} / \mathrm{mL}$ ) using a Polytron at 25,000 rpm over a 30 second period three times on ice. The lysates were centrifuged at $20,400 \mathrm{~g}$ for 20 mins at $4^{\circ} \mathrm{C}$. The amount of protein was quantified from $5 \mu \mathrm{L}$ of the homogenates via the Bicinchoninic acid (BCA) method using a Pierce ${ }^{\circledR}$ BCA protein assay kit (prod\# 23227, Thermo Scienctific, USA). Ice-cold acetone (in an amount four times the volume of homogenates) was added and incubated over night at $-20^{\circ} \mathrm{C}$ in order to precipitate proteins. The precipitate was collected by centrifugation at $20,400 \mathrm{~g}$ for $20 \mathrm{mins}$ at $4^{\circ} \mathrm{C}$ and washed with $500 \mu \mathrm{L}$ ice-cold acetonitrile. Next, precipitate was centrifuged as described above and air dried for 5 mins. The precipitate was dissolved in freshly prepared ammonium bicarbonate (ABC, $50 \mu \mathrm{L}, 200 \mathrm{mM}$ ) containing $0.1 \%$ 1-propanesulfonicacid-2-hydroxyl-3-meristamido (PHM) in $10 \mathrm{mM} \mathrm{ABC}$ and the resulting solution was incubated at $37^{\circ} \mathrm{C}$ for 10 minsin a rotary shaker. Proteins were reduced by $120 \mathrm{mM}$ 1, 4-dithiothrietol (DTT) at $60^{\circ} \mathrm{C}$ for 30 mins and were alkylated using123 $\mathrm{mM}$ iodoacetamide (IAA) at room temperature in the dark for 1 hour. The mixture was digested using $10 \mu \mathrm{L}$ trypsin (40 $\mathrm{U} / \mu \mathrm{L}$ in $1 \mathrm{mM} \mathrm{HCl}$ ) at $37^{\circ} \mathrm{C}$ overnight followed by heat-inactivation of the enzyme at $90^{\circ} \mathrm{C}$ for 10 mins. After cooling to room temperature, $2 \mathrm{U}$ PNGase $\mathrm{F}$ was added and incubated at $37^{\circ} \mathrm{C}$ overnight. The sample was dried by SpeedVac and stored at $-30^{\circ} \mathrm{C}$ until the day of use. Protein concentration was adjusted to 100 pgusing de-ionized water and applied to glycoblotting, as described below. 


\section{7. $N$-glycans release from mouse serum glycoproteins}

Mouse serum ( $\mathrm{n}=5$ of each sex of HD transgenic and control mice) was pretreated for the release of $\mathrm{N}$-glycans and followed by glycoblotting in order to enrich the $\mathrm{N}$-glycans prior to MALDITOF/MS and TOF/TOF analysis. Briefly, $10 \mu$ Lofmouse serum was diluted six times in freshly prepared ABC (0.33 M)-PHM (0.4\% in $10 \mathrm{mM} \mathrm{ABC)-DTT} \mathrm{mixture} \mathrm{(120mM)} \mathrm{at} \mathrm{a} \mathrm{1:1.5:1} \mathrm{(v/v)}$ ratio. Internal standard (A2amide, 110 pmole) was added and the mixture was incubated at $60^{\circ} \mathrm{C}$ for 30 mins. Iodoacetamide (IAA, $10 \mu \mathrm{L}$ of $123 \mathrm{mM}$ ) was added and incubated at room temperature for 1 hour in the dark. Trypsin $(5 \mu \mathrm{L}, 40 \mathrm{U} / \mu \mathrm{L}$ in $1 \mathrm{mM} \mathrm{HCl})$ was added and the mixture was incubated at $37^{\circ} \mathrm{C}$ for 1 hour. The digested mixture was heat inactivated $\left(90^{\circ} \mathrm{C}, 10\right.$ mins) and cooled to room temperature. PNGase F (5U) was added and incubated at $37^{\circ} \mathrm{C}$ for 2 hours. $20 \mu \mathrm{L}$ of digested mixture was applied directly to glycoblotting protocol.

\subsection{Releasing $O$-glycans from brain tissue and serum glycoproteins}

Sample preparation and trypsin digestion were performed as previously described. Ammonium carbamate ('a' $+5 \mathrm{mg}$, where ' $\mathrm{a}$ ' is the volume original homogenate used) was added to enzyme digested mixture and incubated at $60^{\circ} \mathrm{C}$ for 40 hrs. The digested mixture was subsequently washed (four times with $500 \mu \mathrm{L}$ water) and neutralized (one time with $500 \mu \mathrm{L} 150 \mathrm{mM}$ acetic acid) with each process being accompanied by drying via SpeedVac. The dried sample was stored at $-30^{\circ} \mathrm{C}$ until use. 400 pgof protein dissolved in deionized water was used for glycoblotting protocol.

\subsection{Releasing glycan moieties from brain tissue GSLs}

Perfused and subfragmented mouse brain tissue ( $\mathrm{n}=5$ of each sex of HD transgenic and control mice) was homogenized in PBS $(20 \mathrm{mg} / \mathrm{mL})$ using the same method described previously. The 
lysates were centrifuged at $100 \mathrm{~g}$ for 10 mins at $4^{\circ} \mathrm{C}$ and the supernatant was transferred into another $15 \mathrm{~mL}$ Falcon tube. The precipitate was dissolved with $600 \mu \mathrm{L}$ of PBS and sonicated. The mixture was centrifuged at $800 \mathrm{~g}$ for $10 \mathrm{mins}$ at $4^{\circ} \mathrm{C}$ and the supernatant was mixed with the first homogenates. The whole homogenates were centrifuged at $13,000 \mathrm{~g}$ for $10 \mathrm{mins}$ at $4^{\circ} \mathrm{C}$ and the resulting precipitate was again dissolved in $500 \mu \mathrm{L}$ PBS. $5 \mu \mathrm{L}$ of this mixture was used for the BCA assay. The remaining solution was centrifuged $\left(13,000 \mathrm{~g}\right.$, for 10 mins at $\left.4^{\circ} \mathrm{C}\right)$. The precipitate was dissolved, successively, with a mixture of $1 \mathrm{~mL}$ chloroform/methanolto produce three solutions (1:2,1:1 and 2:1 v/v). Each solution was subsequently sonicated for approximately10 mins. Each extraction was followed by centrifugation at $800 \mathrm{~g}$ and $4^{\circ} \mathrm{C}$ and the resulting supernatantswere collected in another $15 \mathrm{~mL}$ Falcon tube. The resulting supernatants (total lipids) were dried at room temperature via SpeedVac. The total lipids were suspended in 1 $\mathrm{mL}$ chloroform/methanol(1:1 v/v) and sonicated. Ozone was generated from oxygen using a benchtop generator (NG81-NO3, Nigorikawakogyo, Japan) at a flow setting of $1 \mathrm{~mL} / \mathrm{min}$. The output from the ozone generator was bubbled for 5 mins and the reaction was quenched by passing $\mathrm{N}_{2}$ gas for a minute. The pipettes were rinsed with $\mathrm{CHCl}_{3} / \mathrm{MeOH}(1: 1 \mathrm{v} / \mathrm{v})$, and the resulting solution was dried by SpeedVac. Next, MeOH:0.5 M NaOMe/MeOH (4:1 v/v) was added to the dried sample and allowed to stand for 30 mins at room temperature. The reaction mixture was transferred to a $1.5 \mathrm{~mL}$ eppendorf tube, neutralized with $6 \mu \mathrm{L}$ concentrated acetic acid and then dried. Asample equivalent to $500 \mu$ gof protein adjusted with de-ionized water was used for glycoblotting protocol.

\subsection{Releasing glycan moieties from serum GSLs}

A100 $\mu \mathrm{L}$ of freeze-dried serum was used to analyze serum glycan moieties released from GSLs. Briefly, GSLs were extracted in 3mL of chloroform:MeOH mixtures at 1:2, 1:1, 2:1 (v/v) and 
achloroform:MeOHl:water mixture at 2:5:1 (v/v). Each step was accompanied by sonication for 10 mins and centrifugation at 800 rpm for 10 mins. The resulting supernatants of each extraction were collected together in another $15 \mathrm{~mL}$ Falcon tube. The remaining steps were performed in accordance with the procedure of brain GSL-omics described above.

\subsection{Glycoblotting (enrichment, on bead esterification, and labelling total glycomes)}

$500 \mu \mathrm{L}$ of BlotGlyco ${ }^{\circledR} \mathrm{H}$ beads $(10 \mathrm{mg} / \mathrm{mL}$ ) was added to the wells of MultiScreen Solvinert filterplate and the water was removed by vacuum. Digested mixtures of brain tissue ( $20 \mu \mathrm{L})$ containing100-500 $\mu$ g protein (specified in each $\mathrm{N}$-, $\mathrm{O}$-, and GSL-glycan analysis) and serum containing IS (A2amide for $\mathrm{N}$-glycans, GN4 for $\mathrm{O}$-and GSL-glycans, which accurate concentration was known) were added together to each well along with $180 \mu \mathrm{L}$ of $2 \%$ AcOH/Acetonitril (ACN). The plate was incubated at $80^{\circ} \mathrm{C}$ for 45 mins followed by two successive washings using $200 \mu \mathrm{L}$ each of $2 \mathrm{M}$ guanidine- $\mathrm{HCl}$ in $16.6 \mathrm{mM} \mathrm{ABC}$ and, water and $1 \%$ triethylamine in $\mathrm{MeOH}$. After unreactive hydrazide functional groups were acetyl capped using $10 \%$ acetic anhydride in $\mathrm{MeOH}$ at room temperature for 30 mins, the remaining acetic anhydride was removed by vacuum. Each well was washed two times with $10 \mathrm{mM} \mathrm{HCl}, \mathrm{MeOH}$ and dioxane, consecutively. $150 \mathrm{mM}$ MTT was added and incubated at $60^{\circ} \mathrm{C}$ for 90 mins for on bead methyl esterification. Next, washing was performed using $200 \mu \mathrm{L}$ of dioxane, water, methanol and water. For an effective transimination reaction, $20 \mathrm{mM} \mathrm{Na}$ (aminoxy) acetyl tryptophanarginine methyl ester (aoWR) (for brain tissue $\mathrm{N}$ - and serum $\mathrm{O}$-glycans) and $50 \mathrm{mM}$ $O$-benzylhydroxylamine (BOA) (for serum $N$-, brain tissue $O$-and GSL-glycans) were added and incubated at $80^{\circ} \mathrm{C}$ for 45 mins. Labeled glycans were eluted with $100 \mu \mathrm{L}$ water. The aoWRtagged solution was further purified using a hydrophilic interaction chromatography purification plate (Mass PREPTM HILIC $\mu$ Elution Plate, Waters, MA). The resulting glycan solutions were 
concentrated by SpeedVac and subsequetly dissolved in $10 \mu \mathrm{L}$ of distilled water. In general, BOA-based labeling should be employed due to its chemical stability, easy handling, and lower cost. However, it is known that use of aoWR reagent often gives much improved MS spectra because of its higher ionization potential than that of BOA reagent $[47,56]$. In the present study, we used aoWR labeling in cases for brain tissue N-glycans and serum O-glycans enrichment processes in order to purify tagged tissue N-glycans from highly complicated mixtures containig heavy contaminations and extremely low concentration of serum O-glycans, respectively.

\subsection{Mass spectrometric analysis}

The recovered glycans from mice brain tissues and serum, which were dissolved in $10 \mu \mathrm{l}$ water, were analyzed after being spotted on MTP 384 target plate (Polished steel TF, Bruker Daltonics) and crystallized together with matrices [10 mg/mL DHB in 30\% ACN for aoWR-labeled glycans, and DHB/DHB-Na ${ }^{+}\left(10 \mathrm{mg} / \mathrm{mL} \mathrm{DHB}^{-\mathrm{Na}^{+}}\right.$in 30\% ACN, 9:1) for BOA-labeled $O$ - and GSLglycans]. MALDI-TOF/MS data were acquired on an Ultraflex III (Bruker Daltonics, Bremen, Germany) equipped witha reflector and controlled by the FlexControl 3.0 software package according to the general protocol. All spectra were obtained using reflectron mode with an acceleration voltage of $25 \mathrm{KV}$, a reflector voltage of $26.3 \mathrm{KV}$, pulsed ion extraction of $160 \mathrm{~ns}$ in the positive mode and sum up to 2,000 shots for each spot. Further fragment analysis was performed by MALDI-TOF/TOF analysis (Bruker Daltonics, Bremen, Germany). Annotation of the MS and TOF/TOF data was done using the FlexAnalysis 3.0 software package (Bruker Daltonics GmbsH, Bremen, Germany, $\mathrm{S} / \mathrm{N}=6$ and quality factor threshold of 30). The experimental masses were used to predict possible glycan compositions reported on http://web.expassy.org/glycomod/ and CFG (http://www.functionalglycomics.org). The Lipid Bank (http://lipidbank.jp/) and in-house databases were used to estimate GSL-glycan structures. 
Glycan profiling was performed basiclly by focusing on exclusively known glycan structures sourced from the brain/nervous system and serum of Mus musculus and Ratus norvegicusand other mammals (especially known glycoforms sourced from human brain). After the peaks for the detected glycans were selected, absolute quantification was performed by comparative analysis, i.e., the area under each isotopic peak was normalized to the internal standard. Glycan expression levels were determined analytically as HD transgenic (R6/2) versus the control group (BCF1) ( $\mathrm{n}=3$ and 5 for brain tissue and serum, respectively, and $\mathrm{N}=2$, where $\mathrm{n}$ and $\mathrm{N}$ are the number of samples and experiments, respectively) and the corresponding statistical significance was calculated using the student t-test. 


\section{Results}

\subsection{Strategy of total glycomics of HD transgenic (R6/2) and WT (BCF1) mice}

The comprehensive glycomics of 12-week-old HD transgenic mice (R6/2) and the WT littermate (BCF1) mice were performed by a general protocol outlined in Figure 1. Firstly, the brain and serum proteins (for $\mathrm{N}$ - and $\mathrm{O}$-glycomics) were directly solubilized, reduced and alkylated. Preparation of tryptic digested glycopeptides facilitated the release of $\mathrm{N}$-and $\mathrm{O}$-glycans by means of peptide $\mathrm{N}$-glycosidase F (PNGase F) digestion and non-reductive ß-elimination, respectively. Likewise, GSLs were extracted from the brain tissue and serum using a chloroform/methanol mixture. Glycans were released from GSLs using ozonolysis and alkaline degradation. All glycan analysis followed the same glycoblotting process, viz., released glycans were selectively captured onto high density hydrazide beads (BlotGlyco ${ }^{\circledR} \mathrm{H}$ ) for highly efficient purification of oligosaccharides followed by on-bead methyl esterification to stabilize sialic acid(s) for the simultaneous quantitation of neutral and sialylated oligosaccharides by MALDI-TOF/MS. Finallythe labeled oliogosaccharides were recovered as aoWR or BOA derivatives via imine exchange that enabled highly sensitive and quantitative analysis via MALDI-TOF/MS. It is noteworthy that the efficient ionization of glycans after aoWR derivatization and following selective capturing and HILIC purification of glycans enhanced the removal of impurities in case for brain tissue $\mathrm{N}$-glycomics and drastically improved the signal-to-noise ratio. This was found to be especially effective for higher molecular weight oligosaccharides such as multi-antennary $N$ glycans [47] and extremely low concentration of serum O-glycan analysis [50]. Glycans were measured by MALDI-TOF/MS as a single proton and sodium adduct molecular ions ([M + $\mathrm{H}]^{+}$and $[\mathrm{M}+\mathrm{Na}]^{+}$for aoWR and BOA labeled, respectively). The results of these analyses were used to select target ions for further analysis by tandem TOF/TOF to investigate possible 
structures, sequence positions and branching patterns. However, it should also be noted that, since MS-based analysese can provide only possible $N$-glycans by estimating sugar compositions predicted using known $N$-glycome database, further NMR-based structural characterization using synthetic standards may be necessary to determine precise structures with respect to stereochemistry and branching positions in the glycoside linkages.

\subsection{Brain $N$-glycomics analysis of HD transgenic and WT mice}

Using glycoblotting-based sample preparation combined with MALDI-TOF/MS analysis of brain total glycomics of HD transgenic (R6/2) and WT mice (BCF1), we could efficiently estimate the type of $\mathrm{N}$-, $\mathrm{O}$-, GSL-glycan moieties. As a preliminar trial, we first analyzed the whole brain (20 mg randomly taken) of perfused and unperfused BCF1 mice to assess the dominant glycans present in the brain, enabling us to establish an in-house database, and to exclude the possible impingement of $N$-glycans from serum. While perfused males BCF1 (BCF1 $\delta^{\lambda}$ ) and unperfused males BCF1(BCF1 ${ }^{1}$ ) were found to have $240.71 \pm 53.22$ and $20.45 \pm 7.26$ pmoles, respectively, perfused females BCF1 (BCF1 우) and unperfuse females BCF1 (BCF1 ㅇ) were found to have $591.07 \pm 141.67$ and $173.54 \pm 39.45$ pmoles, respectively $(\mathrm{p}<0.01$ for male and $\mathrm{p}<0.05$ for female mice). We have found significant differences in the amount of $N$-glycans found in the perfused compared to the unperfused mouse brain tissues. Only trace amounts of terminal sialic acid containing $\mathrm{N}$-glycans were found in the perfused mice as compared to the unperfuse mice. Surprisingly, total $N$-glycan expression levels in the brain tissue were found to be higher in female BCF1 mice as compared to males in both the perfused and unperfused groups when the glycoblotting ptorocol was used directly for whole brain tissues in which the striatum and cortex had not been separated. We also found that the $N$-glycans intra-mice deviation was reduced in the perfused mice relative to those of the unperfused mice. As a result, 
we decided to employ isolated striatum and cortex section from the perfused mouse brain tissues for total glycomics of HD transgenic and the control group mice.

We have estimated 75 and $78 \mathrm{~N}$-glycans in the striatum and the cortex, respectively, in which 67 of those were common between the two. There were 9 striatum-specific [Peak \#s 48, 52, 56,63, 69,74,78,83 \& 84] and 11 cortex specific [Peak \#s 45, 47,58,72, 77, 80, 81, 82, 85, 86, 87] $N$ glycans. All 61 peaks in the striatum (80.3\%) and 64 peaks in the cortex (82.1\%) were reported in the GlycosuitDB (http://www.glycosuitdb.expassy.org/results), as summarized in Table 1. We determined, using database sample sources, that more than $85 \%$ of those $N$-glycans were sourced from the brain of the M. Musculus and R. norvegicus species.

From MALDI-TOF/MS analysis, we are able to estimate high mannose and complex types of $\mathrm{N}$ glycans with the latter existing in bi-, tri-, and tetra-antennary forms, most of which are highly core-fucosylated and have bisecting GlcNAc (Figure 2). Even though quantitatively small in the whole brain, sialylated $N$-glycans were also present with high amount in the cortex than in the striatum (details are shown in section 3.3). Although $\operatorname{Lewis}^{\mathrm{x}}\left(\operatorname{Le}^{\mathrm{x}}\right)$ and sialyl Lewis ${ }^{\mathrm{x}}\left(\mathrm{sLe}^{\mathrm{x}}\right)$ structures could be considered from the compositional analysis, further structural characterization is needed to confirm the existence of these specific antigenic oligosaccharides. While terminal GalNAc residues (peak \#s 34,45, 53,56,61,68) also seem to exist, there was no direct evidence for the presence of NeuGc in HD transgenic and WT mice in the present study. We performed all glycomics experiments independently and at least two times. The molecular weights and estimated compositions of $N$-glycans of the striatum and cortex of the HD model and its control mice were tabulated in Table 1, peak numbers of striatum and serum $N$-glycans were listed in supporting information (Figure S1) and differences in the $N$-glycans expression 
levels in the striatum, cortex and serum of each mouse are given in supporting information (Table S1).

For quantitative analysis, the area of $\mathrm{N}$-glycans detected in MS were normalized with a known concentration of IS (20 pmoles of A2 amide, namely non-natural amidated A2 prepared originally in our laboratory). There were no significant differences in $N$-glycan expression levels in the striatum and cortex of HD transgenic and control group mice (Table 2). However, the groups differ with respect to a few $\mathrm{N}$-glycans that were specific to brain regions and gender as summarized in supporting information (Table S1).

\subsection{Glycotyping analysis of brain $N$-glycans}

To facilitate the glycome profiling analysis and their changes between HD transgenic and control group mice, we applied the glycotyping analysis approach [49,53,57]. Here, we focused on the high mannose, fucosylated, bisecting-GlcNAc and antennary type of complex $N$-glycan moieties. Typically, we found high mannose (>50\%), core fucosylated (>28\%), bisecting GlcNAc (>35\%) and biantennary (>32\%) as major types of $\mathrm{N}$-glycans in the striatum and cortex of HD transgenic and WT mice of both sexes. While the high mannose types were decreased, those of core fucosylated, bisecting-GlcNAc and biantennary types of $\mathrm{N}$-glycans were increased in the HD transgenic mice compared to that of the WT mice, albeit these numbers statistically insignificant (Table 3). Using TOF/TOF analysis, possible major glycoforms were high mannose, corefucosylated, biantennary and bisecting-GlcNAc types of $\mathrm{N}$-glycans (supporting information, Figure S2 A-C). Moreover, hybrid and complex types of $N$-glycans with bisecting-GlcNAc show unfragmented HexHexNAc and $\operatorname{Hex}_{2} \mathrm{HexNAc}_{2}$ (peak \#s 7, 12, 14, 21, 23, 30) under the laser irradiation during the TOF/TOF analysis. This result might indicate that the bisecting GlcNAc 
residue both found in the hybrid and complex type $N$-glycans contribute significantly to the stability of these $N$-glycans under high energy laser irradiation in the TOF/TOF fragmentation processes. Interestingly, it was also demonstrated that Golgi apha-mannosidase, one of the key exoglycosidases in a general biosynthetic pathway of the hybrid and complex type $N$-glycans, can not remove non-reducing Man residues of the key intermediates in the presence of the neighboring bisecting GlcNAc residue [19]. It seems likely that interaction of this GlcNAc with outer-chain sugar residues as well as steric effect might be critical for such unique resistence observed both in the TOF/TOF and enzymatic fragmentation experiments.

\subsection{Serum $N$-glycomics of HD transgenic and WT mice}

Towards the discovery of a potential glyco-biomarker for easy diagnosis and therapy, we extended efforts to profile and quantify $N$-glycans from the sera of HD transgenic and WT mice $(n=5, N=2$, where $n$ and $N$ are the number of samples and experiments, respectively). As estimated, 58 (plus 8 with same $\mathrm{m} / \mathrm{z}$ with different composition) $N$-glycans were found in serum, 51 peaks (85\%) of which were reported in the GlycosuitDB (http://www.glycosuitdb.expassy.org/results). All ofthe peaks (m/z) specific to serum and common with brain $N$-glycans compostion are shown in Table 1 and the spectra containing peak numbers are shown in supporting information (Figure S1).

Quantitatively, the amount of $N$-glycans released from the serum of BCF1 $\delta$ and Pis shown in Table 2. $N$-glycans decreased in male and female HD transgenic (with the female decrease being slightly less pronounced) as compared to the WT mice. We have selected a few peaks that show a significant difference in $\mathrm{N}$-glycan expression levels between HD transgenic and WT mice (Table 4). The largest peak in the serum $N$-glycan level (peak\#42) is higher in the control group than in the HD transgenic mice, and the peak of the fucosylated form of this glycan (peak \#48) is 
higher for the HD transgenic mice. We specified peak 42 using TOF/TOF analysis (supporting information, Figure S3). From glycotyping analysis, we have estimated that core-fucoylated $N$ glycans are higher in HD transgenic than the control group mice (increased from 12.1 to $38.6 \%$ in male and 29.9 to $43.8 \%$ in female mice, Figure 3). Moreover, high levels of disialic acid (majority of $\mathrm{N}$-glycolylneuraminic acid) containing biantennary type $\mathrm{N}$-glycans were found in the HD transgenic and WT mice. However, the levels of high mannose and bisecting type $\mathrm{N}$ glycans were small compared to those in the striatum and cortex of the same experimental mice (data not shown).

\subsection{Avidin-biotin complex lectin staining of brain tissue sections}

We applied avidin conjugated lectins specific to high mannose (ConA), core-fucosylated (LCA), bisecting-GlcNAc (PHA-E 4 ), LacNAc (DSA), terminal sialic acid (SSA) and non-sialylated Tantigen (PNA) to study the localization of glycoconjugates in brain tissue (supporting information, Figure S6). Around the nucleus, we were able to observe less intensely stained regions of the striatum and cortex of R6/2 by ConA (highly pronounced in male R6/2), the striatum of R6/2 $\delta$ and cortex of R6/2 $q$ by LCA, and both the striatum and cortex of R6/2 $q$ by PHA-E $_{4}$ as compared to those of the WT mice. In addition, SSA and PNA staning both in the striatum and cortex confirmed the presence of the terminal sialic acid and O-glycans, respectively. In general, there were significant differences in the staining intensity with the lectins in the brain sections of HD transgenic and WT mice dependent on the total amount of $\mathrm{N}$ glycans expression levels. However, the results stained by means of LCA and PHA-E4 did not support the specific glycoform alterations suggested by the comprehensive glycomics described above, while the ConA staining clearly indicated significant changes found in $N$-glycan analysis. Conventional PAS approach appeared to give non-specific staining in all brain regions. 


\section{6. $O$ - glycomics of HD transgenic and WT mice}

We profiled the possible mucin type $O$-glycans from the brains and sera of the HD transgenic and WT mice. The total amount of mucin type $O$-glycans in the striatum and cortex was found in increased levels in male and decrease in female HD transgenic mice (Table 2 and supporting information, Table S2). The estimated composition of mucin type $O$-glycans in the striatum, cortex and serum were summarized in supporting in formation Table S2A. Regarding the brain tissue, Tn antigen (HexNAc, $\mathrm{m} / \mathrm{z}$ 349.11) was only found to have decreased in the cortex of R6/2 o compared to the same section of BCF1 9 . Core 1 or $\mathrm{T}$ antigen (HexNAcHex, m/z 511.22) was exclusively detected in the HD transgenic mice (supporting information Table S2 A). Core 3 $\left(\mathrm{HexNAc}_{2}, \mathrm{~m} / \mathrm{z} 552.2\right.$ ) increased in $\mathrm{R} 6 / 2$ ${ }^{\Uparrow}$ in both the striatum and cortex whereas it decreased in $\mathrm{R} 6 / 2$ ㅇ Levels of HexNAcNeuAc ( $\mathrm{m} / \mathrm{z}$ 640.3), which is supposed to be the final product that can no longer be an acceptor for other glycosytransferases, increased in the HD transgenic mice, except in the cortex of female R6/2 mice (Supporting information Table S2 B).

From $100 \mu \mathrm{L}$ of serum, mucin type $O$-glycans levels were found in decreased amounts in the HD transgenic mice, albeit the decrease is statistically insignificant. However, core 1 (HexHexNAc) decreased in R6/2 ascompared to BCF1 and, core $2\left(\operatorname{Hex}_{1} \mathrm{HexNAc}_{2}\right)$ was not detected in the HD transgenic mice. In addition to mucin type, we also found other modification such as $O$ mannosyl, $O$-fucosyl, and $O$-GlcNAcylation, all of which are potential markers (data not shown).

\subsection{Glycosphingolipidomics of brain tissue of HD transgenic and WT mice}

The carbohydrate moieties of unprotected (native) GSLs were released by extraction of total lipids from the brain tissue and serum, with subsequent liberation by ozonolysis giving rise to GSL-aldehyde and glycan release by alkaline degradation [58]. Using the glycoblotting technique, GSL-glycans were efficiently captured and further structural estimation and 
quantitative analysis by MALDI-TOF/MS and TOF/TOF analysis was performed. From the brain tissue, we have profiled GM3, GM2, GMl, GD1a, GD2 (except in striatum of male mouse), GA1 (only in the cortex of both sexes) and Type IIA glycosyl ceramide (only in the striatum of

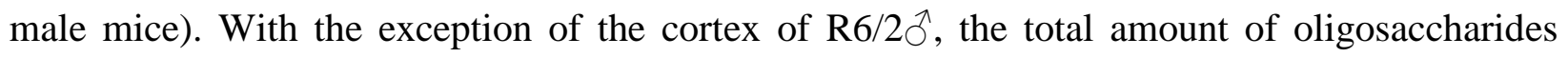
released from GSLs increased in the striatum and cortex of the R6/2 compared to that of BCF1 (Table 2). Focusing on a-series gangliosides expression levels, the relative abundance was found to be GD1a>> GM1 > GM2 > GM3. GD1a is exclusively increased in the striatum (brain region that is most severely affected by HD) (Table5). The possible sequence of GD1a is shown in supporting information Figure S4. Ganglioside expression levels were found to differ between male and female mice as well as between intra-brain regions.

\subsection{Serum glycosphingolipidomics}

According to the same approach used in the brain GSL-omics, the amounts of serum gangliosides (containing NeuAc and NeuGc) and globo-series were estimated (Figure 4, supporting information Figure S5). The compositions and amounts of GSL-glycans (pmoles \pm SD) are summarized in Table 6. Total GSL-glycans were decreased by 39\% and 36\% in male and female HD transgenic mice, respectively, compared to that of the control group mice. This reduction was highly pronounced for NeuGc-containing a-series gangliosides, such as GM2NeuGc, GM1-NeuGc and GD1a-NeuGc. GM2-NeuGc was found to be the most abundant ganglioside (>76\%), decreasing $32 \%$ and $40 \%$ in male and female $\mathrm{HD}$ transgenic mice, respectively, compared to that of the control group mice. From these results, we determined GM2-NeuGc to be a promising candidate as a potential glyco-biomarker in HD and should be studied further. 


\section{Discussion}

Neurodegenerative diseases are, collectively, the leading cause of disability in the elderly, and Huntington's disease is a hallmark of genetic disorders. In most cases, scientists have chosendiagnostic techniques based on physical examinations such as CT, PET, MRI, and fMRIscans, immunohistochemistryand neurochemistry, all of which are used to determinethe levels of amino acids, lipids, small peptides and metabolic pathways in brain [59-62]. When A. B. Young predicted [59] that, whthin the next 40 years, "we will have silver bullets for neurodegenerative diseases,"she targeted biomarkers by blood proteomics and/or metabolomics to be used as screening tools and predictors of subsequent diseases. We targeted the glycobiomarkers that are enzymatically or chemically released from glycoproteins and glycolipids. Thematically, we proposed and established the total glycomics of R6/2 and BCF1 for comprehensive structural estimation and quantitative analysis of total glycomes, viz., $\mathrm{N}-$-, $\mathrm{O}-$, and GSL-glycans. To the best of our knowledge, this is the first study on the total glycomics of Huntington's disease.

From the whole brain $N$-glycomics, we found no significant difference in the amount of $N$ glycomes expression levels between R6/2 and BCF1. However, in serum, $N$-glycans were found in decresed levels in HD transgenic mice. Core-fucosylated, bisecting-GlcNAc and biantennary complex type $\mathrm{N}$-glycans were slightly increased in the brain tissue of HD transgenic mice.We performed a glycan-type focus lectin staining to crosscheck $N$-glycan analysis and confirmed that the localization of glycoconjugates in brain tissue were not significantly different between HD transgenic and WT mice. Conventional PAS showed no specific stained regions in brain tissue of HD transgenic and WT mice. 
The total amount of $O$-glycans found in the striatum and cortex was elevated in males and lower in females from the R6/2 group. We found that the amount of $O$-glycans was reduced in the serum of R6/2. The most dominant mucin type of $O$-glycan in the brain tissue was found to be core 3 (GlcNAc $\beta 1 \rightarrow 3 \mathrm{GalNAc}$ ) which was elevated in $\mathrm{R} 6 / 2$ o and lower in $\mathrm{R} 6 / 2$ \& compared to the corresponding BCF1 group. Consequently, we believe that this particular $O$-glycan could serve as a promising mucin type $O$-glycan biomarker for HD pathophysiology. With respect to serum $O$-glycomics, Core 1 levels were decreased and, Core 2 was not detected in R6/2 at all.

The total amount of GSL-glycans detected in the striatum of male HD transgenic mice was three times higher than that for the control group mice. However, the glycans released from the cortex of the same HD transgenic mice were lower than those in the conrol group mice. The whole brain regions of female HD transgenic mice displayed higher levels of GSL-glycans relative to those of the WT mice. GD1a was drastically increased in the striatum of HD transgenic mice. Most gangliosides are synthesised by liver and secreted into the serum. Ganglioside composition can be altered as a result of liver disease of various etiologies. Since the serum ganglioside concentration, especially that of GM2-NeuGc, was markedly reduced in mice with metastatic VM tumors [63], our study can provide further evidence demonstrating the alteration of liver functions due to the effect of HD. Consequently, GM2-NeuGc in serum was determined as a potential glyco-biomarker in the ganglioside-family. In serum, GSL-glycans are more strongly expressed in male (both R6/2 and BCF1) as opposed to female mice. This difference in the glycan expression levels may be linked to sex hormones or gender sensitivity to the overexpression of circulatory HTT. The higher levels of gangliosides in HD model mice might be due to inadequate amounts of hexosaminidase in lysosomal compartments, suggesting that HD transgenic mice experienced the same symptoms of GSL lysosomal storage disease[19,64]. 
As stated early, it is likely that HD might affect significantly cortex as well as striatum, and also even other parts of the body. Comparison of the intra-brain region glycome may uncover the significance of the region-specific sensitivity of the neuronal and glial cells to the cytotoxic effect of the huntingtin aggregates. The total amount of $N$ - and GSL-glycans were found in increased levels in the striatum and the cortex, respectively. The samples that were taken from the same mouse brain $(\mathrm{p}<0.001)$. However, there was no significant difference in total amounts of $\mathrm{O}$-glycans between the striatum and cortex (Figure 5A-C). The increase of $\mathrm{N}$-glycans quantities in the striatum is the related to the higher neuronal numbers [65]. Lower $N$-glycans and higher GSL-glycans expression levels in the cortex indicate selective vulnerability of the HD cortices (especially in the later weeks) and accumulation of gangliosides due to the low activity of specific hydrolase enzymes. The difference in total glycomes expression levels between male and female mice is a useful finding as it would facilitate sex focused diagnosis and therapeutic targets.

The decrease mechanism and biochemical effects of HD to other sequelae of diseases, including diabetes mellitus, changes in liver function and the aggregation of proteins in different cellular compartments (as characteristic neurodegenerative disease neuropathological lesions involve deposition of abnormal proteins) is area of great interest. In addition to glycome profiling of thebrain, serum total-glycomics provides an alternative method for quantifying the glycome expression levels of HD to help assess the liver function. Furthermore, the alteration of specific glycomescan predict whether HD transgenic mice are predisposed for other sequela.

It has been known that an omnipresent huntingtin (HTT) proteinis responsible for the aggregation of amyloid like proteins, termed as "protein-cancers", in the bodies of mice. The gradual increase in the amount of aggregates significantly affects liver (the source of most serum 
glycoproteins) and pancreas (where the whole sugar metabolism is governed) function. Some researchers believe that age-dependent HD neurological defects are accompanied by progressive decline in glucose tolerance that ultimately leads to diabetes mellitus and insulin deficiency [66]. This hypothesis is further supported by the observation that diabetes frequently develops in HD patients and transgenic mice [67]. In contrast, other researchers also claim that HD does not increase the possible risk of diabetes mellitus, albeit their results do not exclude changes in glucose tolerance in end-stage HD patients or in patients with juvenile onset HD [68]. The present result reveals that the expression levels of FUT8 mRNA were significantly increased in the liver and $N$-glycans possessing alpha1,6-fucose was increased in diabetic mice (db/db) relative to the db/+ of the control group [69]. Core fucosylation by FUT8 might increase the survival rate of HD transgenic mice. Miyoshi et al. reported that in HCC, chronic hepatitis and liver cirrhosis, the expression of FUT8 is quite low in comparison to that of a normal liver. Further, increased levels of fucosylated proteins in serum can be used as tumour markers because numerous serum proteins are produced in liver [70,71]. Combining with the current serum $\mathrm{N}$ glycomics, it is considered that HD transgenic mice might share a similar glycosylation effect as that observed in case of the diabetic mice, in which the liver function might be influenced significantly by the progression of the disease. However, identifying the specific protein to which those glycans attach required further investigation. 


\section{Conclusion}

In this study, we demonstrated the importance of the total glycomics of HD transgenic (R6/2) and WT mice (BCF1) using the glycoblotting method [35-41,47,56]. This technique enabled us to efficiently estimate the structure and quantify of the total glycomes derived from brain and serum glycoproteins and glycosphingolipids. Brain tissue and serum total glycomics were key in determining the amount of $\mathrm{N}-$, $\mathrm{O}-$, and GSL-glycans associated with post-translational modifications as well as the characterization of glycan repertoiers as novel glyco-biomarkers. Accordingly, we determined that the trend and expression levels of total glycomes were significantly different between the HD transgenic and control group mice. Glycans play critical roles in nervous system development, regeneration and synaptic plasticity [13] and their structural richness makes promising candidates as potential disease markers [48].Therefore, glycoblotting-based glycome profiling of HD transgenic mice is an alternative approach towards the identification of potential glyco-biomarkers specific to CNS disorders viz., Alzheimer's, Parkinson's, Spinocerebellarataxia, and Amyotrophic lateral sclerosis. Webelieve the present studywill be of great assistance in the field of neuroscienceand future drug discovery. 


\section{Acknowledgements}

This work was partly supported by the Minsitry of Education, Culture, Sports, Science, and Technology Japan (MEXT) and JSPS KAKENHI Grant Number 25220206, JSPS Core-to-Core

Program, and by Japan Science and Technology Agency (JST) through a grant for "Development of Systems and Technology for Advanced Measurement and Analysis (SENTAN)" and "The Matching Program for innovations in Future Drug Discovery and Medical Care". 


\section{References}

[1] M. DiFiglia, E. Sapp, K. O. Chase, S. W. Davies, G. P. Bates, J. P. Vonsattel, N. Aronin, Aggregation of huntingtin in neuronal intranuclear inclusions and dystrophic neurites in brain, Science 277 (1997) 1990-1993.

[2] J. B. Martin, Molecular basis of the neurodegenerative disorders, N. Engl. J. Med. 340 (1999) 1970-1980.

[3] N. W. Kowall, R. J. Ferrante, J. B. Martin, Patterns of cell loss in Huntington's disease, Trends Neurosci. 10 (1987) 2-29.

[4] A. H. Sharp, S. J. Loev, G. Schilling, S. H. Li, X. J. Li, J. Bao, M. V. Wagster, J. A. Kotzuk, J. P. Steiner, A. Lo, Widespread expression of Huntington's disease gene (IT15) protein product, Neuron 14 (1995) 1065-1074.

[5] G. Bates, Huntingtin aggregation and toxicity in Huntington's disease, Lancet 361 (2003) 164-1644.

[6] S. H. Li, X. J. Li, Huntingtin - protein interactions and the pathogenesis of Huntington's disease, Trends Genet. 20 (2004) 146-154.

[7] L. Mangiarini, K. Sathasivam, M. Seller, B. Cozens, A. Harper, C. Hetherington, M. Lawton, Y. Trottier, H. Lehrach, S. W. Davies, G. P. Bates, Exon 1 of the HD gene with an expanded CAG repeat is sufficient to cause a progressive neurological phenotype in transgenic mice, Cell 87 (1996) 49-506. 
[8] The Huntington's Disease Collaborative Research Group, A novel gene containing a trinucleotide repeat that is expanded and unstable on Huntington's disease chromosomes, Cell 72 (1993) 971-983.

[9] C. M. Ambrose, M. P. Duyao, G. Barnes, G. P. Bates, C. S. Lin, J. Srinidhi, S. Baxendale, H. Hummerich, H. Lehrach, M. Altherr, J. Wasmuth, A. Buckler, D. Church, D. Housman, M. Berks, G. Micklem, R. Durbin, A. Dodge, A. Read, J. Gusella, M.E. MacDonald, Structure and expression of the Huntington's disease gene: evidence against simple inactivation due to an expanded CAG repeat, Somat Cell Mol Genet. 20 (1994) 27-38.

[10] L. M. Morales, J. Estévez, H. Suárez, R. Villalobos, L. Chacín de Bonilla, E. Bonilla, Nutritional evaluation of Huntington disease patients, Am J Clin Nutr. 50 (1989) 145-150.

[11] A. Trejo, M. C. Boll, M. E. Alonso, A. Ochoa, L. Velasquez, Use of oral nutritional supplements in patients with Huntington’s disease, Nutrition 21 (2005) 889-894.

[12] P. S. Harper, Huntington’s disease, W. B. Saunders, London, 1991.

[13] R. Barone, L. Sturiale, A. Palmigiano, M. Zappia, D. Garozzo, Glycomics of pediatric and adulthood diseases of the central nervous system, J Proteomics 75 (2012) 5123 - 5139.

[14] C. C. Chen, S. Engelborghs, S. Dewaele, N. Le Bastard, J. J. Martin, V. Vanhooren, C. Libert, P. P. De Deyn, Altered serum glycomics in Alzheimer's disease: A potential blood biomarker? Rejuvenation Res. 13 (2010) 439-444.

[15] V. Vanhooren, S. Dewaele, C. Libert, S. Engelborghs, P. P. De Deyn, O. Toussaint, F. Debacq-Chainiaux, M. Poulain, Y. Glupczynski, C. Franceschi, K. Jaspers, I. van der Pluijm, J. 
Hoeijmakers, C. C. Chen, Serum N-glycan profile shift during human aging, Exp Gerontol. 45 (2010) 738-743.

[16] J. L. Price, D. L. Powers, E. T. Powers, J. W. Kelly, Glycosylation of the enhanced aromatic sequon is similarly stabilizing in three distinct reverse turn contexts, Proc Natl Acad Sci U S A 108 (2011) 14127-14132.

[17] R. Kleene, M. Schachner, Glycans and neural cell interactions, Nat Rev Neurosci. 5 (2004) 195-208.

[18] S.-I. Hakomori, Y. Zhang, Glycosphingolipid antigens and cancer therapy, Chem.Biol. 4 (1997) 97-104.

[19] Y. J. Chen, D. R. Wing, G. R. Guile, R. A. Dwek, D. J. Harvey, S. Zamze, Neutral $N$ glycans in adult rat brain tissue - complete characterization reveals fucosylated hybrid and complex structures, Eur. J. Biochem. 251(1998) 691-703.

[20] S. Zamze, D. J. Harvey, Y. J. Chen, G. R. Guile, R. A. Dwek, D. R. Wing, Sialylated Nglycans in adult rat brain tissue - awidespread distribution of disialylated antennae in complex and hybrid structures, Eur. J. Biochem. 258 (1998) 243-270.

[21] W. Chai, C. T. Yuen, H. Kogelberg, R. A. Carruthers, R. U. Margolis, T. Feizi, A. M. Lawson, High prevalence of 2-mono- and 2, 6-disubstituted manol-terminating sequences among O-glycans released from brain glycopeptides by reductive alkaline hydrolysis, Eur. J. Biochem. 263 (1999) 879-888. 
[22] S. J. North, S. Chalabi, M. Sutton-Smith, A. Dell, S. M. Haslam, Mouse and Human Glycomes, in Hand book of glycomics (Eds.: R. D. Cummings, J. M. Pierce), Academic Press, New York, 2009, pp. 263-327.

[23] A. K. Callesen, J. S. Madsen, W. Vach, T. A. Kruse, O. Mogensen, O. N. Jensen, Serum protein profiling by solid phase extraction and mass spectrometry: A future diagnostics tool? Proteomics 9 (2009) 1428-1441.

[24] K. L. Abbott, K. Aoki, J.-M. Lim, M. Porterfield, R. Johnson, R. M. O'Regan, L. Wells, M. Tiemeyer, M. Pierce, Targeted glycoproteomic identification of biomarkers for human breast carcinoma, J. Proteome Res. 7 (2008) 1470-1480.

[25] S. Srivastava, Move over proteomics, here comes glycomics, J. Proteome Res. 7 (2008) 1799.

[26] N. H. Packer, C.-W. Von der Lieth, K. F. Aoki-Kinoshita, C. B. Lebrilla, J. C. Paulson, R. Raman, P. Rudd, R. Sasisekharan, N. Taniguchi, W. S. York, Frontiers in glycomics: Bioinformatics and biomarkers in disease. An NIH White Paper prepared from discussions by the focus groups at a workshop on the NIH campus, Proteomics 8 (2008) 8-20.

[27] P. Gagneux, A. Varki, Evolutionary considerations in relating oligosaccharide diversity to biological function, Glycobiology 9 (1999) 747-755.

[28] J. N. Arnold, R. Saldova, U. M. A. Hamid, P. M. Rudd, Evaluation of the serum N-linked glycome for the diagnosis of cancer and chronic inflammation, Proteomics 8 (2008) 3284-3293.

[29] S. A. Brooks, M. V. Dwek, U. Schumacher, Functional and Molecular Glycobiology. BIOS Scientific Publishers Limited, Oxford, U.K., 2002. 
[30] H. Lis, N. Sharon, Protein glycosylation: Structural and functional aspects, Eur. J. Biochem. 218 (1993) 1-27.

[31] K. Lakshmi, K. M. Lara, Glycomics analysis: an array of technology, ACS Chem. Biol. 4 (2009) 715-732.

[32] A. Varki, R. D. Cummings, J. D. Esko, H. H. Freeze,P. Stanley, C. R. Bertozzi,G. W. Hart, M. E. Etzler, Essential of Glycobiology, 2nd ed., Cold Spring Habor Laboratory Press, Cold Spring Harbor, New York, 2009.

[33] R. Kannagi, N. A. Cochran, F. Ishigami, S. Hakomori, P. W. Andrews, B. B. Knowles, D. Solter, Stage-specific embryonic antigens (SSEA-3 and -4) are epitopes of a unique globo-series gangliosides isolated from human teratocarcinoma cells, EMBO J. 2 (1983) 2355-2361.

[34] J. B. Lee, J. M. Kim, S. J. Kim, J. H. Park, S. H. Hong, S. I. Roh, M. K. Kim, H. S. Yoon, Comparative characteristics of three human embryonic stem cell lines, Mol Cells. 19 (2005) 3138.

[35] X.-E. Liu, L. Desmyter, C.-F. Gao, W. Laroy, S. Dewaele, V. Vanhooren , L. Wang, H. Zhuang, N. Callewaer, C. Libert, R. Contreras, C. Chen, N-glycomics changes in Hepatocellular carcinoma patients with liver cirrhosis induced by hepatitis B virus, Hepatology 46 (2007) 14261435.

[36] T. Kamiyama, H. Yokoo, J. Furukawa, M. Kurogochi, T. Togashi, N. Miura, K. Nakanishi, H. Kamachi, T. Kakisaka, Y. Tsuruga, A. Taketomi, S-I. Nishimura, S. Todo, Identification of novel serum biomarkers of hepatocellular carcinoma using glycomic analysis, Hepatology 57 (2013) 2314-2325. 
[37] K. Nouso, M. Amano, K. Miyahara, M. Y. Ito, K. Miyahara, Y. Morimoto, H. Kato, K. Tsutsumi, T. Tomoda, N. Yamamoto, S. Nakamura, S. Kobayashi, K. Kuwaki, H. Hagihara, H. Onishi, Y. Miyake, F. Ikeda, H. Shiraha, A. Takaki, T. Nakahara, S-I. Nishimura, K. Yamamoto, Clinical utility of high-throughput glycome analysis in patients with pancreatic cancer, J. Gastroenterology 48 (2013) 1171-1179.

[38] K. Miyahara, K. Nouso, S. Saito, S. Hiraoka, K. Harada, S. Takahashi, Y. Morimoto, S. Kobayashi, F. Ikeda, Y. Miyake, H. Shiraha, A. Takaki, M. Amano, S.-I Nishimura, K. Yamamoto, Serum glycan markers for evaluation of disease activity and prediction of clinical course in patients with ulcerative colitis, PLOS ONE 8 (2013) e74861.

[39] M. Takeuchi, M. Amano, H. Kitamura, T. Tsukamoto, N. Masumori, K. Hirose, T. Ohashi, S-I. Nishimura, $N$ - and $O$-glycome analysis of serum and urine from bladder cancer patients using a high-throughput glycoblotting method, JGlycomics\&Lipidomics 3 (2013)108.

[40] J. Bones, S. Mittermayr, N. O’Donoghue, A. Guttman, P. M. Rudd, Ultra performance liquid chromatographic profiling of serum $N$-glycans for fast and efficient identification of cancer associated alterations in glycosylation, Anal Chem. 82 (2010) 10208-10215.

[41] A. Pierce, R. Saldova, U. M. Abd Hamid, J. L. Abrahams, E. W. McDermott, D. Evoy, M. J. Duffy, P. M. Rudd, Levels of specific glycans significantly distinguish lymph node-positive from lymph node-negative breast cancer patients, Glycobiology20 (2010) 1283-1288.

[42] A. Knezevic, O. Gornik, O. Polasek, M. Pucic, I. Redzic, M. Novokmet, P. M. Rudd, A. F. Wright, H. Campbell, I. Rudan, G. Lauc, Effects of aging, body mass index, plasma lipid profiles, and smoking on human plasma N-glycans, Glycobiology20 (2010) 959-969. 
[43] M. Pucic, S. Pinto, M. Novokmet, A. Knezevic, O. Gornik, O. Polasek, L. Vlahovicek, W. Wang, P. M. Rudd, A. F. Wright, H. Campbell, I. Rudan, G. Lauc, Common aberrations from the normal human plasma $N$-glycan profile, Glycobiology 20 (2010) 970-975.

[44] R. Saldova, Y. Fan, J. M. Fitzpatrick, R. W. Watson, P. M. Rudd, Core fucosylation and alpha2-3 sialylation in serum $\mathrm{N}$-glycome is significantly increased in prostate cancer comparing to benign prostate hyperplasia, Glycobiology 21 (2011) 195-205.

[45] S.-I. Nishimura, K. kiikura, M. Kurogochi, T. Masushita, M. Fumoto, H. Hinou, R. kamitani, H. Nakagawa, K. Deguchi, N. Miura, K. Monde, H. Konde, High-throughput protein glycomics: Combined use of chemoselective glycoblotting and MALDI-TOF/TOF mass spectroscopy, Angewu. Chem. Int.Ed. 44 (2005) 91-96.

[46] Y. Miura, M. Hato, Y. Shinohara, H. Kuramoto, J.-i. Furukawa, M. Kurogochi, H. Shimaoka, M. Tada, K. Nakanishi, M. Ozaki, S. Todo, S.-I. Nishimura, BlotGlycoABC ${ }^{\mathrm{TM}}$, an integrated glycoblotting technique for rapid and large scale clinical glycomics, Mol. Cell. Proteomics 7 (2008) 370-377.

[47] J.-i. Furukawa, Y. Shinohara, H. Kuramoto, Y. Miura, H. Shimaoka, M. Kurogochi,M. Nakano, S.-I. Nishimura, Comprehensive approach to structural and functional glycomics based on chemoselective glycoblotting and sequential tag conversion, Anal. Chem. 80 (2008) 10941101.

[48] Y. Kita, Y. Miura, J.-i. Furukawa, M. Nakano, Y. Shinohara, M. Ohno, A. Takimoto, S.-I. Nishimura, Quantitative glycomics of human whole serum glycoprotein based on the standardized protocol for librating N-glycans, Mol. Cell. Proteomics 6 (2007) 1437-1445. 
[49] M. Amano, M. Yamaguchi, Y. Takegawa, T. Yamashita, M. Terashima, J.-i. Furukawa, Y. Miura, Y. Shinohara, N. Iwasaki, A. Minami, S.-I. Nishimura, Threshold in in stage-specific embryonic glycotypes uncovered by a full portrait of dynamic $N$ - glycan expression during cell proliferation, Mol. Cell. Proteomics 9 (2010) 523-537.

[50] Y. Miura, K. Kato, Y. Takegawa, M. Kurogochi, J.-i. Furukawa, Y. Shinohara, N. Nagahori, M. Amano, H. Hinou, S.-I. Nishimura, Glycoblotting - assisted O- glycomics: Ammonium carbamate allows for highly efficient release from glycoproteins, Anal. Chem. 82 (2010) 1002110029.

[51] N. Nagahori, M. Abe, S.-I. Nishimura, Structural and functional glycosphingolipids by glycoblotting with aminooxy-functionalized gold nanaoparticles, Biochemistry 48 (2009) 583594.

[52] S. Hatakeyama, M. Amano, Y. Tobisawa, T. Yoneyama, N. Tsuchiya, T. Habuchi, S-I. Nishimura, C. Ohyama, Serum $N$-glycan alteration associated with renal cell carcinoma detected by high-throughput glycan analysis, J. Urol. 191 (2014) 805-831.

[53] K. Hirose, M. Amano, R. Hashimoto, Y.C. Lee, S.-I. Nishimura, Insight into glycan diversity and evolutionary lineage based on comparative Avio-N-glycomics and sialic acid analysis of 88 Egg Whites of Galloanserae, Biochemistry 50 (2011) 4757-4774.

[54] H. J. An, S.R. Kronewitter, M.L. de Leoz, C. B. Lebrilla, Glycomics and disease markers, Curr Opin Chem Biol. 13 (2009) 601-607.

[55] S. A. Brooks, D. M. Hall, Lectinhistochemistry to detect altered glycosylation in cells and tissues, Methods Mol Biol. 878 (2012) 31-50. 
[56] S. -I. Nishimura, Toward automated glycan analysis, Adv. Carbohydr. Chem Biochem 65 (2011) 219-271.

[57] M. Amano, R. Hashimoto, S.-I. Nishimura, Effects of single genetic damage in carbohydrate recognizing proteins in mouse serum $\mathrm{N}$-glycan profile revealed by simple glycoblotting analysis, ChemBioChem 13 (2012) 451-464.

[58] N. Nagahori, T. Yamashita, M.Amano, S.-I. Nishimura, Effect of ganglioside GM3 synthase gene knockout on the glycoprotein $N$-glycan profile of mouse embryonic fibroblast, ChemBioChem 14 (2013) 73-82.

[59] A. B. Young, Four decades of neurodegenerative disease research: How far we have come! J Neurosci. 29 (2009) 12722-12728.

[60] I. Bohanna, N. Georgiou-Karistianis, A. J. Hannan, G. F. Egan, Magnetic resonance imaging as an approach towards identifying neuropathological biomarkers for Huntington's disease, Brain Res Rev. 58 (2008) 209-225.

[61] S. J. Sawiak, N. I. Wood, G. B. Williams, A. J. Morton, T. A. Carpenter, Use of magnetic resonance imaging for anatomical phenotyping of the R6/2 mouse model of Huntington's disease, Neurobiol Dis. 33 (2009) 12-19.

[62] E. Cepeda-Prado, S. Popp, U. Khan, D. Stefanov, J. Rodríguez, L. B. Menalled, D. DowEdwards, S. A. Small, H. Moreno, R6/2 Huntington's disease mice develop early andprogressive abnormal brain metabolism and seizures, J. Neurosci. 32 (2012) 6456-6467.

[63] M. Cotterchio, T. N. Seyfried, Serum gangliosides in mice with metastatic and nonmetastatic brain tumors, J. Lipid Res. 35 (1994) 10-14. 
[64] K. Sango, M. P. McDonald, J. N. Crawley, M. L. Mack, C J. Tifft, E. Skop, C. M. Starr, A. Hoffman, K. Sandhoff, K. Suzuki, R. L. Proia, Mice lacking both subunits of lysosomal betahexosaminidase display gangliosides and mucopolysaccharides, Nature Genetics 14 (1996) 348352.

[65] H. Heinsen, M. Strik, M. Bauer, K. Luther, G. Ulmar, D. Gangnus, G. Jungkunz, W. Eisenmenger, M. Götz, Cortical and striatal neurone number in Huntington's disease, Acta Neuropathol. 88 (1994) 320-333.

[66] O. A. Andreassen, A. Dedeoglu, V. Stanojevic, D. B. Hughes, S. E. Browne, C. A. Leech, R. J. Ferrante, J. F. Habener, M. F. Beal, M. K. Thomas, Huntington's disease of the endocrine pancrease : Insuline deficiency and diabetes mellitus due to impaired insulin gene expression, Neurobiology of Disease 11 (2002) 410-424.

[67] M. Bjorkqvist, M. Fex, E. Renstrom, N. Wierup, A. Petersen, J. Gil, K. Bacos, N. Popovic, J-Y. Li, F. Sundler, P. Brundin, H. Mulder, The R6/2 transgenic mouse model of huntington's disease develops diabetes due to deficient $\beta$ - cell mass and exocytosis, Human Molecular Genetics 14 (2005) 565-574.

[68] T. W. Boesgaard, T. T. Nielsen, K. Josefsen, T. Hansen, T. JØrgensen, O. Pedersen, A. NØrremØlle, J. E. Nielsen, L. Hasholt, Huntington's disease doesn't appear to increase the risk of diabetes mellitus, Journal of Neuroendocrinology 21 (2009)770-776.

[69] N. Itoh, S. Sakaue, H. Nakagawa, M. Kurogochi, H. Ohira, K. Deguchi, S.-I. Nishimura, M. Nishimura, Analysis of $\mathrm{N}$-glycan in serum glycoproteins from $\mathrm{db} / \mathrm{db}$ mice and humans with type 2 diabetes, Am J Physiol Endocrinol Metab 293 (2007) E1069-E1077. 
[70] E. Miyoshi, K. Moriwaki, T. Nakagawa, Biological function of fucosylation in cancer biology, J Biochem. 143 (2008) 725-729.

[71] E. Miyoshi, N. Uozumi, K. Noda, N. Hayashi, M. Hori, N. Taniguchi, Expression of alpha16 fucosyltransferase in rat tissues and human cancer cell lines, Int. J. Cancer 72 (1997) 11171121. 
Table 1. Estimated composition of $N$-glycans from striatum, cortex and serum of R6/2 and BCF1. These peaks are common to both the disease and control groups in this study. The asterisk $(*)$ shows peak number 16 and 23 containing NeuGc that are detected only in serum, not in brain tissues. GlcNAc, $N$-acetlyglucoseamine; Man, Mannose; Deoxyhexose, fucose; HexNAc, $N$ acetylhexoseamine ( $N$-acetylglucosamine or $N$-acetylgalactoseamine depends on the description); Hex, hexose (Mannose, glucose and galactose depend of the description); NeuAc, $N$-acetylneuraminic acid; and NeuGc, $N$-glycolylneuraminic acid.

\begin{tabular}{|c|c|c|c|}
\hline Brain and serum Common $N$-glycans & & Brain & Serum \\
\hline Composition & $\begin{array}{c}\text { ExPasy } \\
\text { MW }\end{array}$ & Peak \# & Peak \# \\
\hline$(\mathrm{HexNAc}) 1+(\mathrm{Man}) 3(\mathrm{GlcNAc}) 2$ & 1095.40 & 3 & 1 \\
\hline (Hex)2 + (Man)3 (GlcNAc)2 & 1216.42 & 4 & 2 \\
\hline (HexNAc)1 (Deoxyhexose)1 + (Man)3 (GlcNAc)2 & 1241.45 & 5 & 3 \\
\hline (Hex)1 (HexNAc)1 + (Man)3 (GlcNAc)2 & 1257.45 & 6 & 4 \\
\hline (Hex)3 + (Man)3 (GlcNAc)2 & 1378.48 & 8 & 5 \\
\hline$(\mathrm{Hex}) 2(\mathrm{HexNAc}) 1+(\mathrm{Man}) 3(\mathrm{GlcNAc}) 2$ & 1419.50 & 11 & 6 \\
\hline (HexNAc)2 (Deoxyhexose)1 + (Man)3 (GlcNAc)2 & 1444.53 & 12 & 7 \\
\hline (Hex)1 $($ HexNAc)2 $+($ Man)3 (GlcNAc)2 & 1460.53 & 13 & 8 \\
\hline (Hex)4 + (Man)3 (GlcNAc)2 & 1540.53 & 15 & 9 \\
\hline (Hex)1 (HexNAc)1 (NeuAc)1 + (Man)3 (GlcNAc)2 & 1548.54 & 17 & 10 \\
\hline (Hex)1 (HexNAc)2 (Deoxyhexose)1 + (Man)3 (GlcNAc)2 & 1606.59 & 21 & 12 \\
\hline (Hex)2 (HexNAc)2 $+($ Man)3 (GlcNAc)2 & 1622.58 & 22 & 13 \\
\hline (HexNAc)3 (Deoxyhexose)1 + (Man)3 (GlcNAc)2 & 1647.61 & 23 & 14 \\
\hline (Hex)5 + (Man)3 (GlcNAc)2 & 1702.58 & 25 & 15 \\
\hline $\begin{array}{r}(\mathrm{Hex}) 2(\mathrm{HexNAc}) 1(\mathrm{NeuAc}) 1+(\mathrm{Man}) 3(\mathrm{GlcNAc}) 2 \\
(\mathrm{Hex}) 1 \text { (HexNAc)1 (Deoxyhexose)1 (NeuGc)1 }+ \text { (Man)3 (GlcNAc)2 }\end{array}$ & 1710.60 & 28 & $16^{*}$ \\
\hline (Hex)2 (HexNAc)2 (Deoxyhexose)1 + (Man)3 (GlcNAc)2 & 1768.64 & 31 & 19 \\
\hline (Hex)1 (HexNAc)3 (Deoxyhexose) $1+$ (Man)3 (GlcNAc)2 & 1809.67 & 33 & 20 \\
\hline (Hex)6 + (Man)3 (GlcNAc)2 & 1864.63 & 35 & 21 \\
\hline $\begin{array}{r}(\mathrm{Hex}) 2(\mathrm{HexNAc}) 2(\mathrm{NeuAc}) 1+(\mathrm{Man}) 3(\mathrm{GlcNAc}) 2 \\
(\mathrm{Hex}) 1 \text { (HexNAc)2 (Deoxyhexose)1 (NeuGc)1 }+ \text { (Man)3 (GlcNAc)2 }\end{array}$ & 1913.68 & 41 & $23 *$ \\
\hline (Hex)1 (HexNAc)3 (Deoxyhexose)2 + (Man)3 (GlcNAc)2 & 1955.72 & 43 & 25 \\
\hline (Hex)2 (HexNAc)3 (Deoxyhexose)1 + (Man)3 (GlcNAc)2 & 1971.72 & 44 & 26 \\
\hline (HexNAc)4 (Deoxyhexose) $2+$ (Man)3 (GlcNAc)2 & 1996.75 & 45 & 27 \\
\hline (Hex)1 (HexNAc)4 (Deoxyhexose) $1+($ Man)3 (GlcNAc)2 & 2012.75 & 46 & 28 \\
\hline (Hex)2 (HexNAc)2 (Deoxyhexose)1 (NeuAc)1 + (Man)3 (GlcNAc)2 & 2059.73 & 50 & 30 \\
\hline (Hex)3 (HexNAc)2 (NeuAc)1 + (Man)3 (GlcNAc)2 & 2075.73 & 52 & 31 \\
\hline (Hex)1 (HexNAc)3 (Deoxyhexose)3 + (Man)3 (GlcNAc)2 & 2101.78 & 53 & 32 \\
\hline (Hex)1 (HexNAc)4 (Deoxyhexose)2 + (Man)3 (GlcNAc)2 & 2158.80 & 57 & 34 \\
\hline
\end{tabular}


(Hex)1 (HexNAc)4 (NeuAc)1 + (Man)3 (GlcNAc)2

(Hex)2 (HexNAc)4 (Deoxyhexose)1 + (Man)3 (GlcNAc)2

(Hex)2 (HexNAc)2 (Deoxyhexose)2 (NeuAc)1 + (Man)3 (GlcNAc)2 (Hex)3 (HexNAc)2 (Deoxyhexose)1 (NeuAc)1 + (Man)3 (GlcNAc)2 (Hex)2 (HexNAc)2 (Deoxyhexose)1 (NeuAc)2 + (Man)3 (GlcNAc)2 (Hex)3 (HexNAc)4 (Deoxyhexose)3 (NeuAc)1 + (Man)3 (GlcNAc)2
2157.78

2174.80

2205.79

2221.79

2350.83

2920.06

\section{Brain specific $N$ - glycans}

Composition

(Deoxyhexose) $1+$ (Man)3 (GlcNAc)2

(Hex)1 + (Man)3 (GlcNAc)2 $(\mathrm{HexNAc}) 2+(\mathrm{Man}) 3(\mathrm{GlcNAc}) 2$

(HexNAc)1 (Deoxyhexose)2 + (Man)3 (GlcNAc)2 (Hex)1 (HexNAc)1 (Deoxyhexose)1 + (Man)3 (GlcNAc)2 $(\mathrm{HexNAc}) 3+(\mathrm{Man}) 3(\mathrm{GlcNAc}) 2$ (Hex)1 (HexNAc)1 (Deoxyhexose)2 + (Man)3 (GlcNAc)2 (Hex)2 (HexNAc)1 (Deoxyhexose)1 + (Man)3 (GlcNAc)2 (Hex)3 (HexNAc)1 + (Man)3 (GlcNAc)2 (HexNAc)2 (Deoxyhexose)2 + (Man)3 (GlcNAc)2 (Hex)1 (HexNAc)3 + (Man)3 (GlcNAc)2 (Hex)1 (HexNAc)1 (Deoxyhexose)1 (NeuAc)1 + (Man)3 (GlcNAc)2 (Hex)3 (HexNAc)1 (Deoxyhexose)1 + (Man)3 (GlcNAc)2 (Hex)1 (HexNAc)2 (Deoxyhexose)2 + (Man)3 (GlcNAc)2 (Hex)3 (HexNAc)2 + (Man)3 (GlcNAc)2

(HexNAc)4 (Deoxyhexose) $1+($ Man)3 (GlcNAc)2 (Hex)2 (HexNAc)1 (Deoxyhexose)1 (NeuAc)1 + (Man)3 (GlcNAc)2 (Hex)3 (HexNAc)1 (Deoxyhexose)2 + (Man)3 (GlcNAc)2 (Hex)3 (HexNAc)1 (NeuAc)1 + (Man)3 (GlcNAc)2 (Hex)1 (HexNAc)2 (Deoxyhexose)1 (NeuAc)1 + (Man)3 (GlcNAc)2 (Hex)2 (HexNAc)2 (Deoxyhexose)2 + (Man)3 (GlcNAc)2 (Hex)3 (HexNAc)2 (Deoxyhexose)1 + (Man)3 (GlcNAc)2 (Hex) $7+($ Man) 3 (GlcNAc)2 (Hex)3 (HexNAc)1 (Deoxyhexose)1 (NeuAc)1 + (Man)3 (GlcNAc)2 (Hex)2 (HexNAc)2 (Deoxyhexose)3 + (Man)3 (GlcNAc)2 (Hex)3 (HexNAc)2 (Deoxyhexose)2 + (Man)3 (GlcNAc)2 (Hex)1 (HexNAc)3 (Deoxyhexose)1 (NeuAc)1 + (Man)3 (GlcNAc)2 (Hex)2 (HexNAc)3 (Deoxyhexose)2 + (Man)3 (GlcNAc)2 (HexNAc)4 (Deoxyhexose) $3+($ Man)3 (GlcNAc)2 (Hex)8 + (Man)3 (GlcNAc)2

\section{ExPasy MW}

1038.38

1054.37

1298.48

1387.51

1403.51

1501.56

1549.57

1565.56

1581.56

1590.59

1663.61

1694.60

1727.61

1752.64

1784.63

1850.69

1856.66

1873.67

1872.65

1897.68

1914.70

1930.69

2026.69

2018.71

2060.76

2076.75

2100.76

2117.78

2142.81

2188.74
58

59

62

63

70

84
35

36

37

39

46

53

\section{Brain}

m/z Peak \#

$1486.6 \quad 1$

$1502.6 \quad 2$

$1746.7 \quad 7$

$1835.8 \quad 9$

$1851.7 \quad 10$

$1949.8 \quad 14$

$1997.8 \quad 16$

$2013.8 \quad 18$

$2029.8 \quad 19$

$2038.8 \quad 20$

$2111.8 \quad 24$

$2156.9 \quad 26$

$2175.9 \quad 29$

$2200.9 \quad 30$

$2232.9 \quad 32$

$2298.9 \quad 34$

$2318.9 \quad 36$

$2321.9 \quad 37$

$2334.9 \quad 38$

$2359.9 \quad 39$

$2362.9 \quad 40$

$2378.9 \quad 42$

$2474.9 \quad 47$

$2481.0 \quad 48$

$2509.0 \quad 49$

$2525.0 \quad 51$

$2563.0 \quad 54$

$2566.0 \quad 55$

$2591.0 \quad 56$

$2637.0 \quad 60$ 
(Hex)1 (HexNAc)5 (Deoxyhexose)1 + (Man)3 (GlcNAc)2 (Hex)2 (HexNAc)3 (Deoxyhexose)3 + (Man)3 (GlcNAc)2

(Hex)2 (HexNAc)3 (Deoxyhexose)1 (NeuAc)1 + (Man)3 (GlcNAc)2 (Hex)3 (HexNAc)3 (Deoxyhexose)2 + (Man)3 (GlcNAc)2 (Hex)1 (HexNAc)4 (Deoxyhexose)1 (NeuAc)1 + (Man)3 (GlcNAc)2 (Hex)2 (HexNAc)4 (Deoxyhexose)2 + (Man)3 GlcNAc)2 (Hex)2 (HexNAc)2 (Deoxyhexose)3 (NeuAc)1 + (Man)3 (GlcNAc)2 (Hex)2 (HexNAc)3 (Deoxyhexose)2 (NeuAc)1 + (Man)3 (GlcNAc)2 (Hex)3 (HexNAc)3 (Deoxyhexose)3 + (Man)3 (GlcNAc)2 (Hex)2 (HexNAc)4 (Deoxyhexose)3 + (Man)3 (GlcNAc)2 (Hex)2 (HexNAc)2 (Deoxyhexose)2 (NeuAc)2 + (Man)3 (GlcNAc)2 (Hex)2 (HexNAc)3 (Deoxyhexose)1 (NeuAc)2 + (Man)3 (GlcNAc)2 (Hex)2 (HexNAc)4 (Deoxyhexose)2 (NeuAc)1 + (Man)3 (GlcNAc)2 (Hex)3 (HexNAc)4 (Deoxyhexose)3 + (Man)3 (GlcNAc)2 (Hex)2 (HexNAc)2 (Deoxyhexose)1 (NeuAc)3 + (Man)3 (GlcNAc)2 (Hex)3 (HexNAc)3 (Deoxyhexose)3 (NeuAc)1 + (Man)3 (GlcNAc)2 (Hex)3 (HexNAc)3 (Deoxyhexose)1 (NeuAc)2 + (Man)3 (GlcNAc)2 (Hex)2 (HexNAc)4 (Deoxyhexose)1 (NeuAc)2 + (Man)3 (GlcNAc)2 (Hex)2 (HexNAc)5 (Deoxyhexose)2 (NeuAc)1 + (Man)3 (GlcNAc)2 (Hex)3 (HexNAc)3 (Deoxyhexose)2 (NeuAc)2 + (Man)3 (GlcNAc)2 (Hex)3 (HexNAc)3 (Deoxyhexose)1 (NeuAc)3 + (Man)3 (GlcNAc)2 (Hex)4 (HexNAc)4 (Deoxyhexose)3 (NeuAc)2 + (Man)3 (GlcNAc)2 (Hex)4 (HexNAc)4 (Deoxyhexose)2 (NeuAc)3 + (Man)3 (GlcNAc)2

$\begin{array}{lll}2215.82 & 2664.1 & 61 \\ 2263.83 & 2712.1 & 64 \\ 2262.81 & 2725.1 & 65 \\ 2279.83 & 2728.1 & 66 \\ 2303.84 & 2766.1 & 67 \\ 2320.86 & 2769.1 & 68 \\ 2351.85 & 2814.1 & 69 \\ 2408.87 & 2871.1 & 71 \\ 2425.89 & 2874.1 & 72 \\ 2466.91 & 2915.2 & 73 \\ 2496.89 & 2973.2 & 74 \\ 2553.91 & 3030.2 & 75 \\ 2611.95 & 3074.2 & 76 \\ 2628.97 & 3077.2 & 77 \\ 2641.93 & 3132.2 & 78 \\ 2716.98 & 3179.2 & 79 \\ 2715.96 & 3192.2 & 80 \\ 2756.99 & 3233.3 & 81 \\ 2815.03 & 3277.3 & 82 \\ 2862.02 & 3338.3 & 83 \\ 3007.06 & 3497.3 & 85 \\ 3373.21 & 3849.5 & 86 \\ 3518.25 & 4008.5 & 87\end{array}$

Serum specific $N$ - glycans Composition

(Hex)1 (HexNAc)1 (NeuGc)1 + (Man)3 (GlcNAc)2 (Hex)2 (HexNAc)1 (NeuGc)1 + (Man)3 (GlcNAc)2 (Hex)1 (HexNAc)2 (NeuAc)1 + (Man)3 (GlcNAc)2 (HexNAc) $5+($ Man)3 (GlcNAc)2 (Hex)2 (HexNAc)2 (NeuGc)1 + (Man)3 (GlcNAc)2 (Hex)2 (HexNAc) $4+($ Man)3 (GlcNAc)2 (Hex)2 (HexNAc)2 (Deoxyhexose)1 (NeuGc)1 + (Man)3 (GlcNAc)2 (Hex)2 (HexNAc)3 (NeuAc)1 + (Man)3 (GlcNAc)2 (Hex)2 (HexNAc)2 (NeuAc)2 + (Man)3 (GlcNAc)2 (Hex)2 (HexNAc)2 (Deoxyhexose)2 (NeuGc)1 + (Man)3 GlcNAc)2

ExPasy
MW
1564.54
1726.59
1751.62
1907.71
1929.67
2028.74
2075.73
2116.76
2204.77
2221.79

\section{Serum} $\mathrm{m} / \mathrm{z} \quad$ Peak \# $1724.6 \quad 11$ $1886.7 \quad 17$ $1911.7 \quad 18$ $2053.6 \quad 22$ $2089.8 \quad 24$ $2174.7 \quad 29$ $2235.8 \quad 31$ $2276.8 \quad 33$ $2378.8 \quad 38$ $2381.9 \quad 39$ 
(Hex)2 (HexNAc)2 (NeuAc)1 (NeuGc)1 + (Man)3 (GlcNAc)2 $2220.77 \quad 2394.8 \quad 40$

(Hex)4 (HexNAc)2 (NeuAc)1 + (Man)3 (GlcNAc)2

(Hex)3 (HexNAc)2 (Deoxyhexose)1 (NeuGc)1 + (Man)3 (GlcNAc)2

$2237.78 \quad 2397.9 \quad 41$

(Hex)2 (HexNAc)2 (NeuGc)2 + (Man)3 (GlcNAc)2 $2236.76 \quad 2410.9 \quad 42$

(Hex)2 (HexNAc)3 (Deoxyhexose)1 (NeuGc)1 + (Man)3 (GlcNAc)2 (Hex)3 (HexNAc)3 (NeuAc)1 + (Man)3 (GlcNAc)2 $2278.81 \quad 2438.9 \quad 43$

(Hex)2 (HexNAc)4 (NeuAc)1 + (Man)3 (GlcNAc)2 $2319.84 \quad 2479.9 \quad 44$

(Hex)4 (HexNAc)4 + (Man)3 (GlcNAc)2 $2352.85 \quad 2498.9 \quad 45$

(Hex)2 (HexNAc)2 (Deoxyhexose)1 (NeuAc)1 (NeuGc)1 + (Man)3 (GlcNAc)2 $2366.83 \quad 2540.9 \quad 47$

(Hex)2 (HexNAc)2 (Deoxyhexose)1 (NeuGc)2 + (Man)3 (GlcNAc)2 $2382.82 \quad 2556.9 \quad 48$

(Hex)3 (HexNAc)3 (Deoxyhexose)1 (NeuAc)1 + (Man)3 (GlcNAc)2 $2424.87 \quad 2585.0 \quad 49$

(Hex)3 (HexNAc)3 (NeuAc)1 (NeuGc)1 + (Man)3 (GlcNAc)2 $2585.90 \quad 2760.0 \quad 50$

(Hex)3 (HexNAc)4 (Deoxyhexose)1 (NeuAc)1 + (Man)3 (GlcNAc)2 $2627.95 \quad 2788.1 \quad 51$

(Hex)2 (HexNAc)2 (Deoxyhexose)3 (NeuAc)2 + (Man)3 (GlcNAc)2 $2642.95 \quad 2817.0 \quad 52$

(Hex)3 (HexNAc)3 (NeuGc)3 + (Man)3 (GlcNAc)2 $2908.98 \quad 3097.1 \quad 54$

(Hex)3 (HexNAc)3 (Deoxyhexose)1 (NeuAc)2 (NeuGc)1 + (Man)3 (GlcNAc)2 $3023.05 \quad 3211.155$

(Hex)3 (HexNAc)3 (Deoxyhexose)1 (NeuGc)3 + (Man)3 (GlcNAc)2 $3055.04 \quad 3243.2 \quad 56$

(Hex)5 (HexNAc)4 (NeuAc)2 + (Man)3 (GlcNAc)2 $3097.09 \quad 3271.3 \quad 57$

(Hex)6 (HexNAc)5 (Deoxyhexose)1 (NeuAc)2 + (Man)3 (GlcNAc)2

(Hex)5 (HexNAc)5 (Deoxyhexose)2 (NeuAc)1 (NeuGc)1 + (Man)3 (GlcNAc)2 $3608.28 \quad 3782.4 \quad 58$

(Hex)4 (HexNAc)5 (Deoxyhexose)3 (NeuGc)2 + (Man)3 (GlcNAc)2 
Table 2. Total glycome (pmole \pm SD) of HD transgenic and control group mice based on protein concentration (100 $\mu \mathrm{g}$ for $N$ - and $O$-glycans, and $100 \mu \mathrm{g}$ protein equivalent of GSL-glycans) and $20 \mu \mathrm{L}$ of serum of each sample.

\begin{tabular}{|c|c|c|c|c|c|}
\hline \multirow[b]{2}{*}{$\begin{array}{c}\text { Total } \\
\text { glycomes }\end{array}$} & \multirow[b]{2}{*}{ Sample } & \multicolumn{2}{|c|}{ Control } & \multicolumn{2}{|c|}{ HD } \\
\hline & & BCF1_ô & BCF1_ㅇ & $\mathrm{R} 6 / 2 \_\mathrm{O}^{\lambda}$ & R6/2_우 \\
\hline \multirow{3}{*}{$N$-glycomes } & Striatum & $426.44 \pm 4.98$ & $404.71 \pm 18.5$ & $401.64 \pm 15.48$ & $379.99 \pm 36.28$ \\
\hline & Cortex & $253.77 \pm 58.73$ & $241.32 \pm 51.05$ & $255.86 \pm 29.62$ & $264.15 \pm 51.65$ \\
\hline & Serum & $306.65 \pm 11.35$ & $250.83 \pm 10.98$ & $246.90 \pm 26.13$ & $233.15 \pm 34.62$ \\
\hline \multirow{3}{*}{$O$-glycomes } & Striatum & $247.83 \pm 88.75$ & $208.69 \pm 82.94$ & $354.33 \pm 194.47$ & $170.42 \pm 81.36$ \\
\hline & Cortex & $148.10 \pm 99.42$ & $158.91 \pm 66.72$ & $170.83 \pm 104.46$ & $114.68 \pm 36.35$ \\
\hline & Serum & $6.48 \pm 3.63$ & $3.60 \pm 2.23$ & $1.84 \pm 0.53$ & $2.21 \pm 0.75$ \\
\hline \multirow{3}{*}{$\begin{array}{c}G S L- \\
\text { glycomes }\end{array}$} & Striatum & $267.55 \pm 35.53$ & $436.93 \pm 130.22$ & $942.35 \pm 124.96$ & $472.72 \pm 127.61$ \\
\hline & Cortex & $1433.72 \pm 192.02$ & $1110.77 \pm 377.88$ & $1185.54 \pm 261.57$ & $1839.34 \pm 383.31$ \\
\hline & Serum & $325.84 \pm 35.44$ & $242.26 \pm 58.10$ & $198.78 \pm 36.98$ & $154.10 \pm 49.87$ \\
\hline
\end{tabular}


Table 3. Glycotyping analysis (in \%) of $N$-glycomes of HD transgenic (R6/2) and WT (BCF1) mice

\begin{tabular}{|c|c|c|c|c|c|c|c|c|c|c|}
\hline \multirow[b]{2}{*}{ Glycotype } & \multirow[b]{2}{*}{$\begin{array}{l}\text { No. } \\
\text { peaks }\end{array}$} & \multicolumn{4}{|c|}{ Striatum } & \multirow[b]{2}{*}{$\begin{array}{c}\text { No. } \\
\text { peaks }\end{array}$} & \multicolumn{4}{|c|}{ Cortex } \\
\hline & & BCF1_O & BCF1_우 & R6/2_ô & R6/2_우 & & BCF1_ô & BCF1_우 & $\mathrm{R} 6 / 2 \_\mathrm{O}^{\mathrm{A}}$ & R6/2_o \\
\hline High Mannose & 7 & 53.9 & 56.0 & 49.6 & 49.8 & 7 & 51.4 & 50.3 & 48.3 & 49.3 \\
\hline Mono-Fucose & 28 & 28.1 & 27.4 & 31.6 & 30.4 & 28 & 28.4 & 28.5 & 30.1 & 30.1 \\
\hline Di-Fucose & 16 & 13.2 & 12.2 & 13.5 & 14.0 & 19 & 15.0 & 15.2 & 15.7 & 14.8 \\
\hline Tri-Fucose & 9 & 1.6 & 1.2 & 1.4 & 1.7 & 8 & 1.9 & 2.0 & 2.1 & 1.8 \\
\hline Mono-Sialic acid & 20 & 2.2 & 1.2 & 2.7 & 1.9 & 19 & 2.4 & 2.6 & 2.5 & 1.9 \\
\hline Di-Sialic acid & 4 & 0.2 & 0.0 & 0.1 & 0.1 & 5 & 0.2 & 0.2 & 0.2 & 0.1 \\
\hline Bisect-GlcNAc & 24 & 35.5 & 34.4 & 38.0 & 37.9 & 23 & 34.8 & 35.3 & 37.0 & 36.3 \\
\hline Bi-antennary & 35 & 27.9 & 26.1 & 31.3 & 31.6 & 29 & 31.6 & 32.1 & 34.8 & 33.5 \\
\hline Tri-antennary & 8 & 1.0 & 0.5 & 1.1 & 1.1 & 12 & 1.4 & 1.5 & 1.9 & 1.4 \\
\hline Tetra-antennary & 2 & 0.2 & 0.2 & 0.3 & 0.4 & 6 & 0.4 & 0.4 & 0.5 & 0.5 \\
\hline
\end{tabular}


Table 4. Selected peaks of $N$-glycans (pmole $\pm \mathrm{SD}$ ) from $10 \mu \mathrm{L}$ serum of HD transgenic and control group mice. Glycan cartoons were constructed using the standard Consortium for Functional nomenclature, i.e., blue square, $N$-acetylglucosamine; yellow square, Nacetylgalactoseamine; red triangle, fucose; green circle, mannose; yellow circle, galactose; purple diamond, $N$-acetylneuraminic acid; and white diamond, $N$-glycolylneuraminic acid.

\begin{tabular}{|c|c|c|c|c|c|c|}
\hline \multirow[b]{2}{*}{$\begin{array}{c}\text { Peak } \\
\text { No. }\end{array}$} & \multirow[b]{2}{*}{$\mathrm{m} / \mathrm{z}$} & \multicolumn{2}{|c|}{ Control } & \multicolumn{2}{|c|}{ HD } & \multirow[b]{2}{*}{ Structure } \\
\hline & & BCF1_ô & BCF1_우 & R6/2_○ & R6/2_o & \\
\hline 24 & 2089.75 & $16.62 \pm 0.84$ & $10.04 \pm 1.09$ & $8.85 \pm 1.11$ & $8.27 \pm 0.96$ & \\
\hline 42 & 2410.06 & $205.83 \pm 17.73$ & $120.28 \pm 6.50$ & $98.80 \pm 8.15$ & $82.06 \pm 9.14$ & \\
\hline 48 & 2556.93 & $16.85 \pm 2.96$ & $43.90 \pm 3.23$ & $63.21 \pm 12.63$ & $69.00 \pm 13.48$ & \\
\hline 49 & 2584.98 & $0.68 \pm 0.26$ & $2.02 \pm 0.86$ & $3.29 \pm 1.37$ & $4.24 \pm 1.66$ & \\
\hline 54 & 3097.12 & $13.89 \pm 2.44$ & $7.40 \pm 0.93$ & $5.29 \pm 1.52$ & $3.99 \pm 0.98$ & \\
\hline
\end{tabular}


Table 5. Quantitative comparison of a-series gangliosides (pmole \pm SD) in brain tissue of R6/2 and BCF1 (from $500 \mu \mathrm{g}$ protein equivalent applied to glycoblotting).

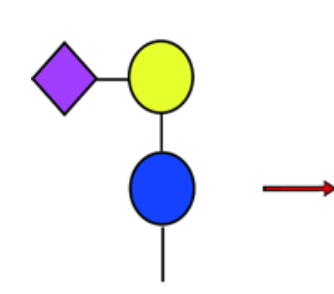

GM3

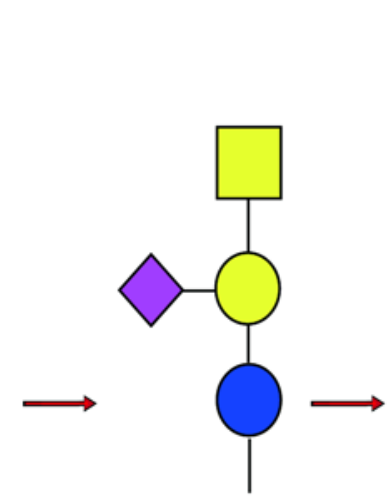

GM2

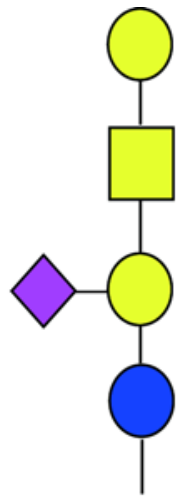

GM1

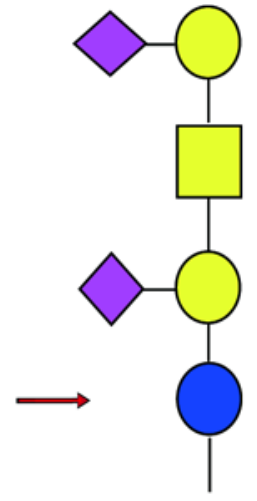

GD1a

\begin{tabular}{ccccc} 
& \multicolumn{4}{c}{ Striatum } \\
Gangliosides & BCF1_o & R6/2_○ & BCF1_+ & R6/2_+ \\
\hline GM3 & $2.61 \pm 4.52$ & $3.03 \pm 5.25$ & $8.17 \pm 0.90$ & $3.24 \pm 2.89$ \\
GM2 & $34.85 \pm 7.77$ & $171.70 \pm 50.38$ & $78.01 \pm 14.96$ & $54.15 \pm 3.63$ \\
GM1 & $341.12 \pm 47.99$ & $1349.14 \pm 321.12$ & $600.00 \pm 130.70$ & $600.27 \pm 127.34$ \\
GD1a & $887.12 \pm 119.58$ & $2658.44 \pm 378.81$ & $1349.81 \pm 493.27$ & $1652.84 \pm 535.48$
\end{tabular}

\begin{tabular}{ccccc} 
& \multicolumn{4}{c}{ Cortex } \\
Gangliosides & BCF1_○ & R6/2_ð & BCF1_o & R6/2_+ \\
\hline GM3 & $17.40 \pm 3.34$ & $11.04 \pm 7.68$ & $8.14 \pm 6.31$ & $22.00 \pm 2.66$ \\
GM2 & $138.52 \pm 44.13$ & $86.45 \pm 28.31$ & $82.70 \pm 25.08$ & $163.20 \pm 36.18$ \\
GM1 & $172.37 \pm 228.75$ & $1459.61 \pm 321.83$ & $1331.16 \pm 388.00$ & $2256.05 \pm 508.23$ \\
GD1a & $4819.79 \pm 736.96$ & $3959.94 \pm 1046.83$ & $3798.44 \pm 1366.83$ & $6112.56 \pm 1365.02$
\end{tabular}


Table 6. Serum glycosphingolipidomics. All serum GSL-glycans compositions, common names and amounts (pmole \pm SD) released from 100 $\mu \mathrm{L}$ of sera from HD transgenic and WT mice are summarized (Hex, glucose or galactose; HexNAc, $N$-acetylgalactoseamine; NeuAc, $N$ acetylneuraminic acid; NeuGc, $N$-glycolylneuraminic acid; and ND, not detected)

\begin{tabular}{llccccc} 
& & & \multicolumn{2}{c}{ Control } & \multicolumn{2}{c}{ HD } \\
GSL-glycan composition & Common name & MS_MW & BCF1_o & BCF1_+ & R6/2_c & R6/2_+ \\
\hline (Hex)2 (HexNAc)1 & GA2 & 673.2 & $3.88 \pm 0.85$ & $4.88 \pm 1.06$ & $2.73 \pm 0.59$ & $2.43 \pm 0.46$ \\
(Hex)2 (NeuAc)1 & GM3 (NeuAc) & 775.3 & $0.60 \pm 0.22$ & $0.64 \pm 0.07$ & $0.54 \pm 0.18$ & $0.63 \pm 0.14$ \\
(Hex)2 (NeuGc)1 & GM3 (NeuGc) & 791.3 & $2.22 \pm 0.27$ & $1.99 \pm 0.34$ & $1.28 \pm 0.48$ & $1.21 \pm 0.26$ \\
(Hex)3 (HexNAc)1 & Asialo GM1 & 835.3 & $2.47 \pm 0.33$ & $2.78 \pm 0.26$ & $2.32 \pm 0.30$ & $3.08 \pm 0.61$ \\
(Hex)2 (HexNAc)1 (NeuAc)1 & GM2 (NeuAc) & 978.4 & $8.54 \pm 1.17$ & $9.05 \pm 3.24$ & $7.94 \pm 1.54$ & $4.67 \pm 1.27$ \\
(Hex)2 (HexNAc)1 (NeuGc)1 & GM2 (NeuGc) & 994.3 & $247.05 \pm 21.27$ & $196.52 \pm 46.14$ & $167.49 \pm 29.07$ & $118.04 \pm 29.92$ \\
(Hex)3 (HexNAc)2 & Forssman Ag/Globo-5 & 1038.4 & $3.13 \pm 0.37$ & $2.76 \pm 0.57$ & $2.01 \pm 0.47$ & $1.93 \pm 0.24$ \\
(Hex)3 (HexNAc)1 (NeuAc)1 & GM1 (NeuAc) & 1140.4 & $1.56 \pm 0.19$ & $1.36 \pm 0.09$ & $1.18 \pm 0.20$ & $1.20 \pm 0.27$ \\
(Hex)3 (HexNAc)1 (NeuGc)1 & GM1 (NeuGc) & 1156.4 & $21.43 \pm 4.21$ & $6.26 \pm 1.78$ & $1.76 \pm 2.06$ & $4.13 \pm 3.38$ \\
(Hex)3 (HexNAc)2 (Deoxyhexose)1 & Type IA/IIA & 1184.4 & $0.76 \pm 0.25$ & ND & ND & ND \\
(Hex)4 (HexNAc)2 & Globo-13 & 1200.4 & $0.43 \pm 0.08$ & 0.55 & ND & 0.24 \\
(Hex)2 (HexNAc)1 (NeuGc)2 & GD2 & 1315.5 & $0.56 \pm 0.06$ & $0.38 \pm 0.09$ & ND & $0.39 \pm 0.08$ \\
(Hex)3 (HexNAc)2 (NeuAc)1 & GalNAc-GM1 (NeuAc) & 1343.5 & $0.71 \pm 0.06$ & $0.60 \pm 0.10$ & $0.97 \pm 0.35$ & $0.57 \pm 0.17$ \\
(Hex)3 (HexNAc)2 (NeuGc)1 & GalNAc-GM1 (NeuGc) & 1359.5 & ND & ND & ND & $0.23 \pm 0.10$ \\
(Hex)3 (HexNAc)1 (NeuAc)2 & GD1a (NeuAc) & 1445.5 & $3.97 \pm 0.81$ & $1.82 \pm 0.39$ & $1.38 \pm 1.12$ & $2.13 \pm 1.98$ \\
(Hex)3 (HexNAc)1 (NeuAc)1 & GD1a (Neu-Ac/Gc) & 1461.5 & $0.92 \pm 0.22$ & $0.63 \pm 0.16$ & $0.56 \pm 0.06$ & $1.08 \pm 0.30$ \\
(NeuGc)1 & & & & &
\end{tabular}




\begin{tabular}{llccccc} 
(Hex)3 (HexNAc)1 (NeuGc)2 & GD1a (NeuGc) & 1477.5 & $26.69 \pm 4.93$ & $11.35 \pm 3.66$ & $8.38 \pm 0.52$ & $11.60 \pm 10.54$ \\
(Hex)5 (HexNAc)2 (Deoxyhexose)1 & Globo-15 & 1508.5 & $0.32 \pm 0.04$ & ND & ND & ND \\
(Hex)4 (HexNAc)2 (NeuGc)1 & Ganglio-a-10/-as-9 & 1521.5 & $0.26 \pm 0.05$ & $0.34 \pm 0.09$ & ND & $0.27 \pm 0.07$ \\
(Hex)3 (HexNAc)2 (NeuGc)2 & GalNac-GD1a & 1680.6 & $0.33 \pm 0.04$ & $0.34 \pm 0.07$ & $0.24 \pm 0.04$ & $0.28 \pm 0.08$ \\
\hline & & Total & $\mathbf{3 2 5 . 8 4} \pm \mathbf{3 5 . 4 4}$ & $\mathbf{2 4 2 . 2 6} \pm \mathbf{5 8 . 1 0}$ & $\mathbf{1 9 8 . 7 8} \pm \mathbf{3 6 . 9 8}$ & $\mathbf{1 5 4 . 1 0} \pm \mathbf{4 9 . 8 7}$
\end{tabular}




\section{Figure Captions}

Figure 1: Schematic diagram of glycoblotting - combinedwith MALDI-TOF/MS analysis for the enrichment of total glycomes from brain tissue of HD transgenic mice (R6/2) and WT mice (BCF1). (a) Perfusion of 12-week-old mice. (b) Homogenization of mouse brain tissue. (c) Trypsin digestionfollowed by PNGase F and ammonium carbamate cleavage of $N$ - and $O$ glycans, respectively; chloroform/methanol extraction and native GSL-glycans cleavage by ozonolysis and subsequent fragmentation by alkaline treatment in the case of oligosaccharides from GSLs. (d) Chemoselective capturing of reducing oligosaccharides on BlotGlyco ${ }^{\circledR}$ H beads. (e) On-bead methyl esterification. (f) Derivatization, glycan release, and finally, MALDI-TOF/MS analysis of either aoWR or BOA labeled $N-$, $O-$, or GSLglycans.

Figure 2: Representative MALDI-TOF/MS spectra of brain tissues $N$-glycans of HD transgenic and WT mice (IS indicates A2 amide used as an internal standard, and $\mathrm{n}=3$ and $\mathrm{N}$ = 2 where $\mathrm{n}$ and $\mathrm{N}$ are the number of the mouse and the experiment, respectively. $\mathrm{M}$, male; $\mathrm{F}$, female.

Figure 3: Glycotyping analysis of fucosylated $N$-glycans from serum R6/2 and BCF1 (Mono$\mathrm{Fu}$, core-fucose; Di-Fu, di-fucose; others, $\mathrm{N}$-glycan types except mentioned; $\mathrm{M}$, male; and F, female).

Figure 4: MALDI-TOF/MS spectrum of serum GSL-glycans in R6/2 and BCF1(IS, internal standard; M, male; and F, female).Glycan cartoons were constructed using the standard Consortium for Functional nomenclature, i.e., blue circle, glucose; yellow circle, galactose; yellow square, $N$-acetylgalactoseamine; purple diamond, $N$-acetylneuraminic acid; and white diamond, $N$-glycolylneuraminic acid. 
Figure 5: Comparison of total glycome expression levels in the striatum and cortex. (A) $\mathrm{N}$ glycans, (B) O-glycans, and (C) GSL-glycans. 


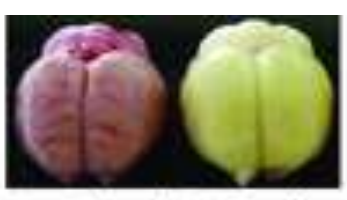

Unperfused \& Perfused

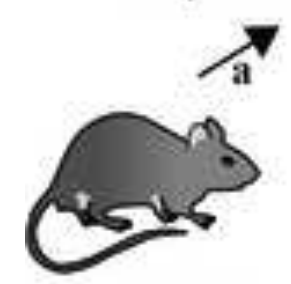

R6/2 \& BCF1
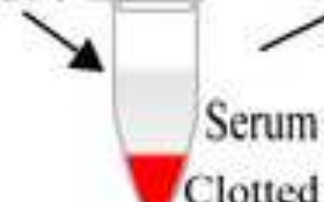

Clotted blood

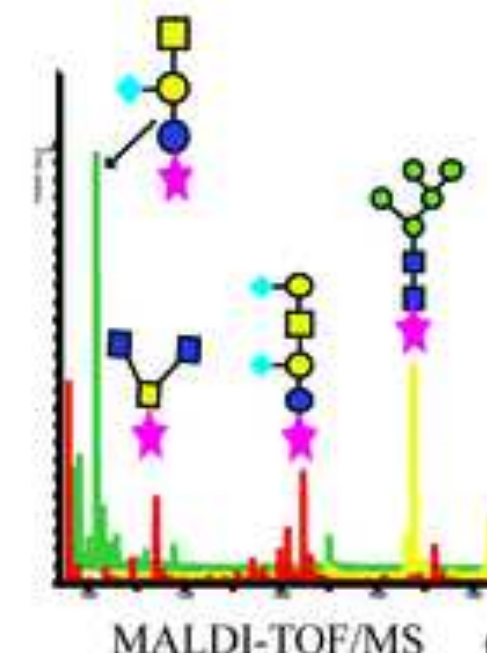

MALDI-TOF/MS
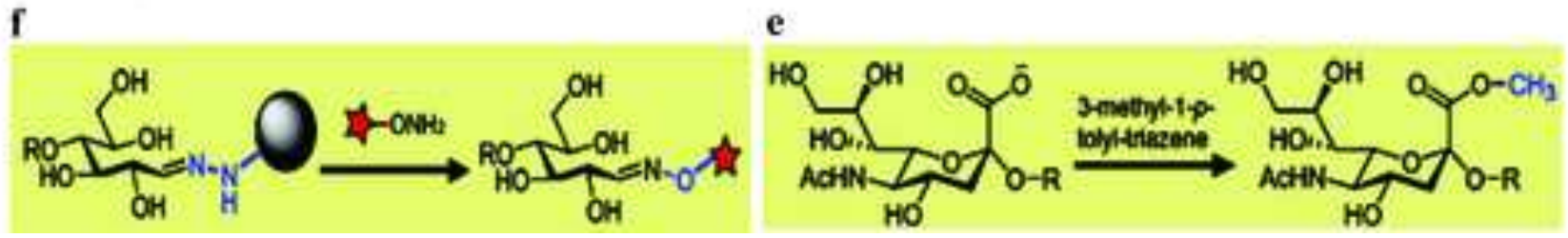

Chemoselective ligation

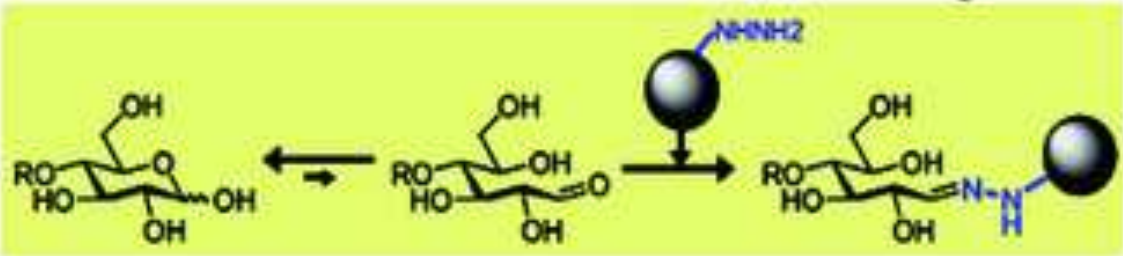

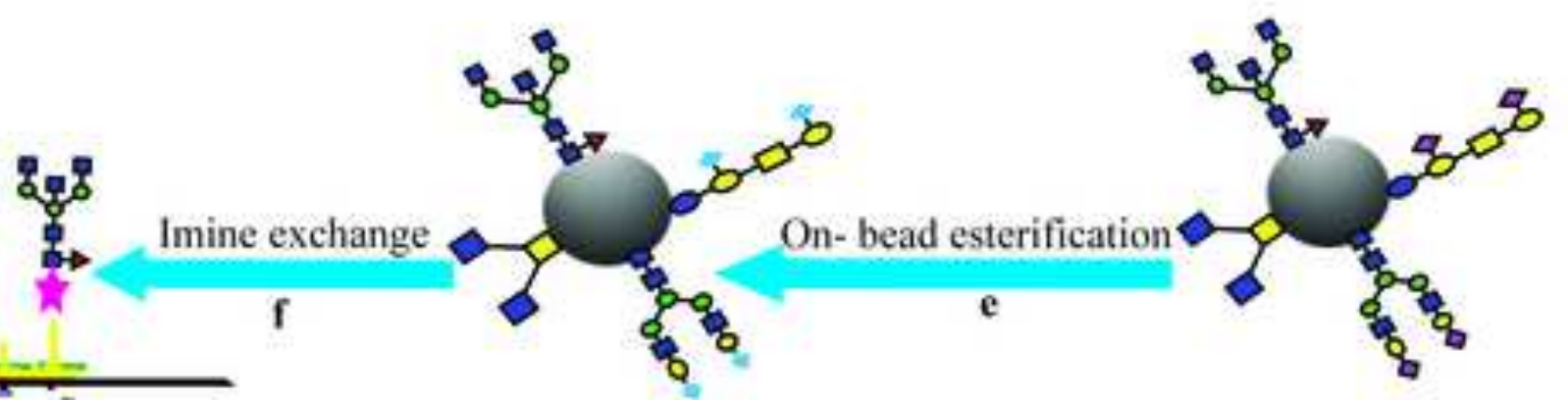
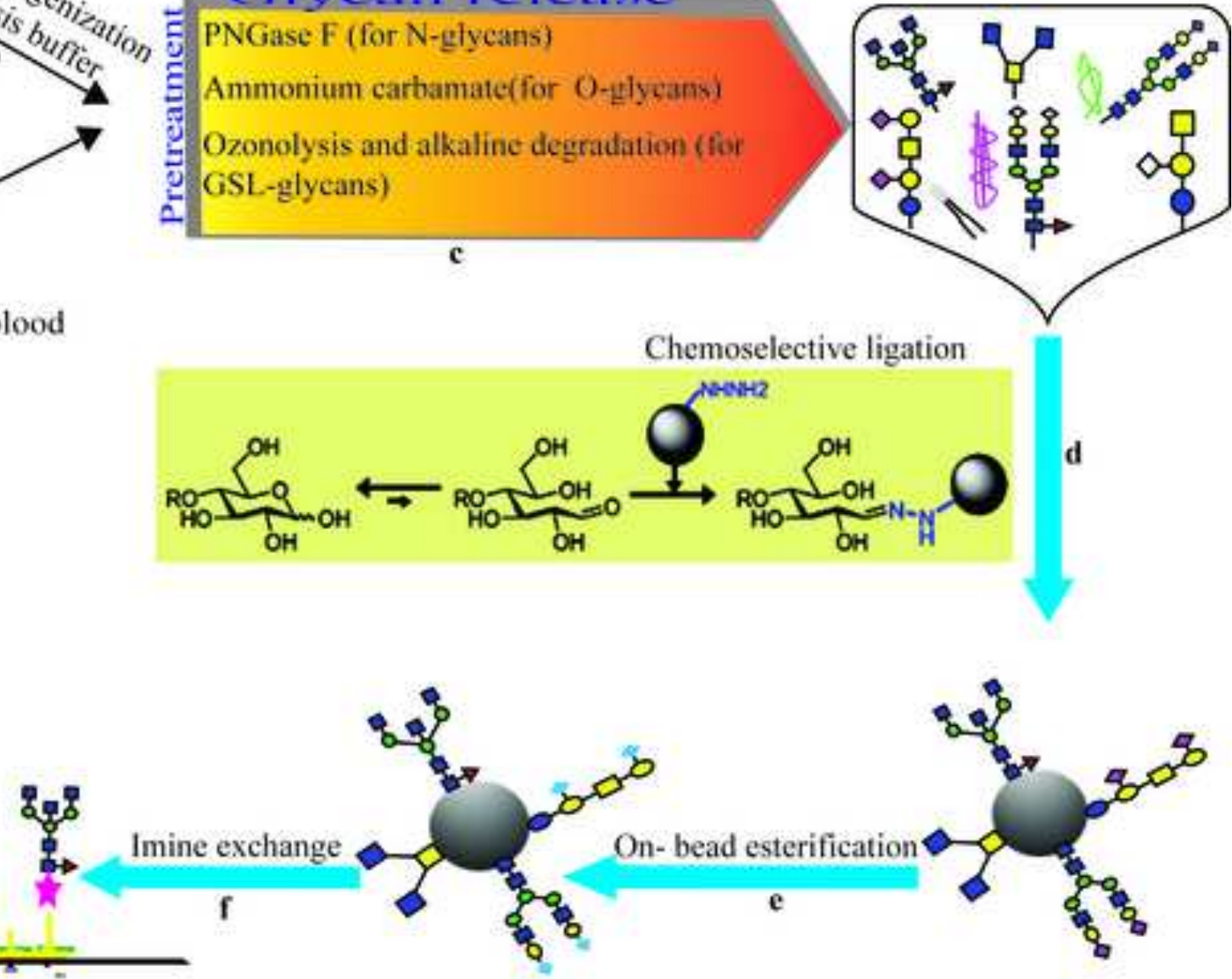

d 


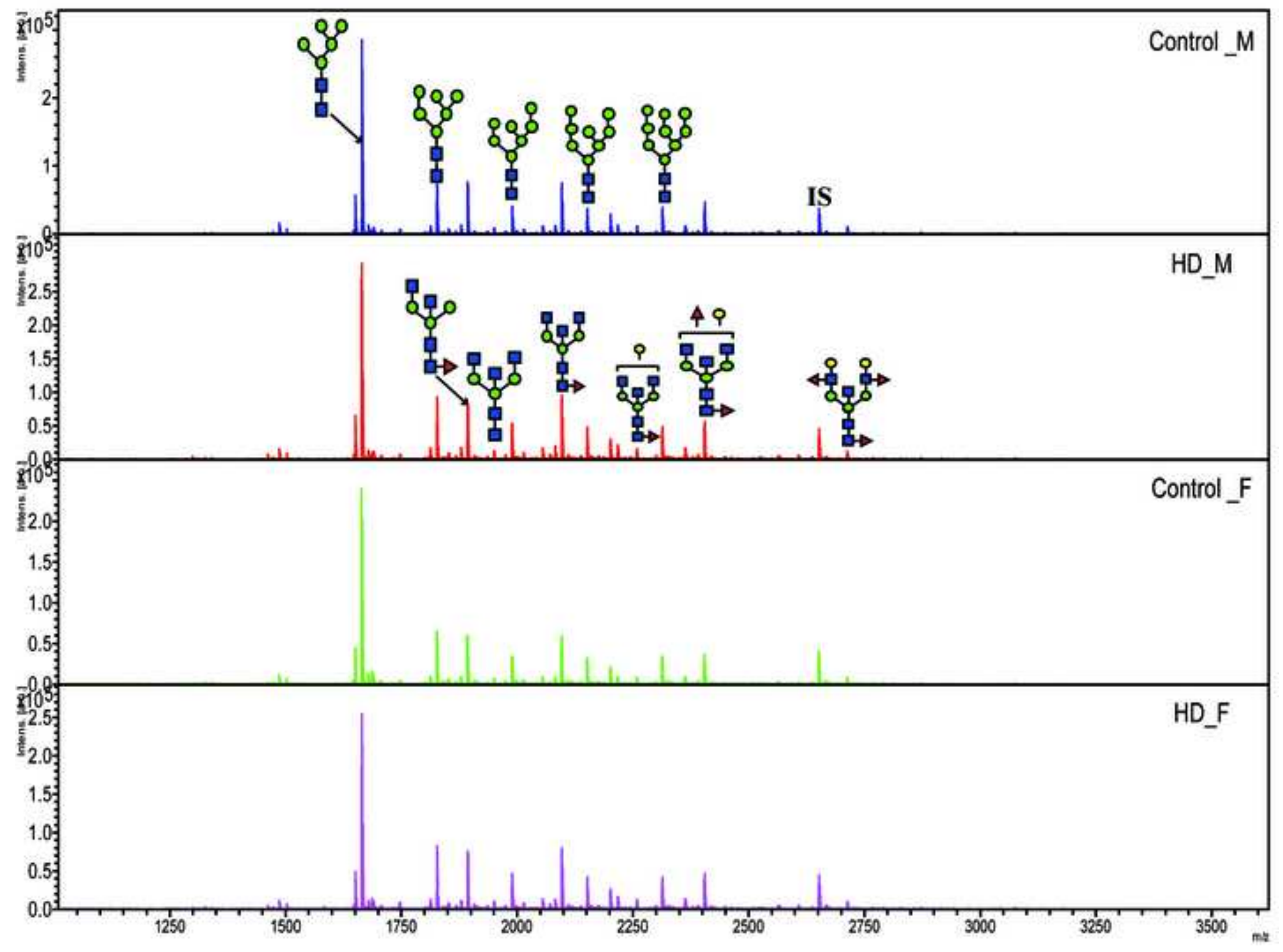




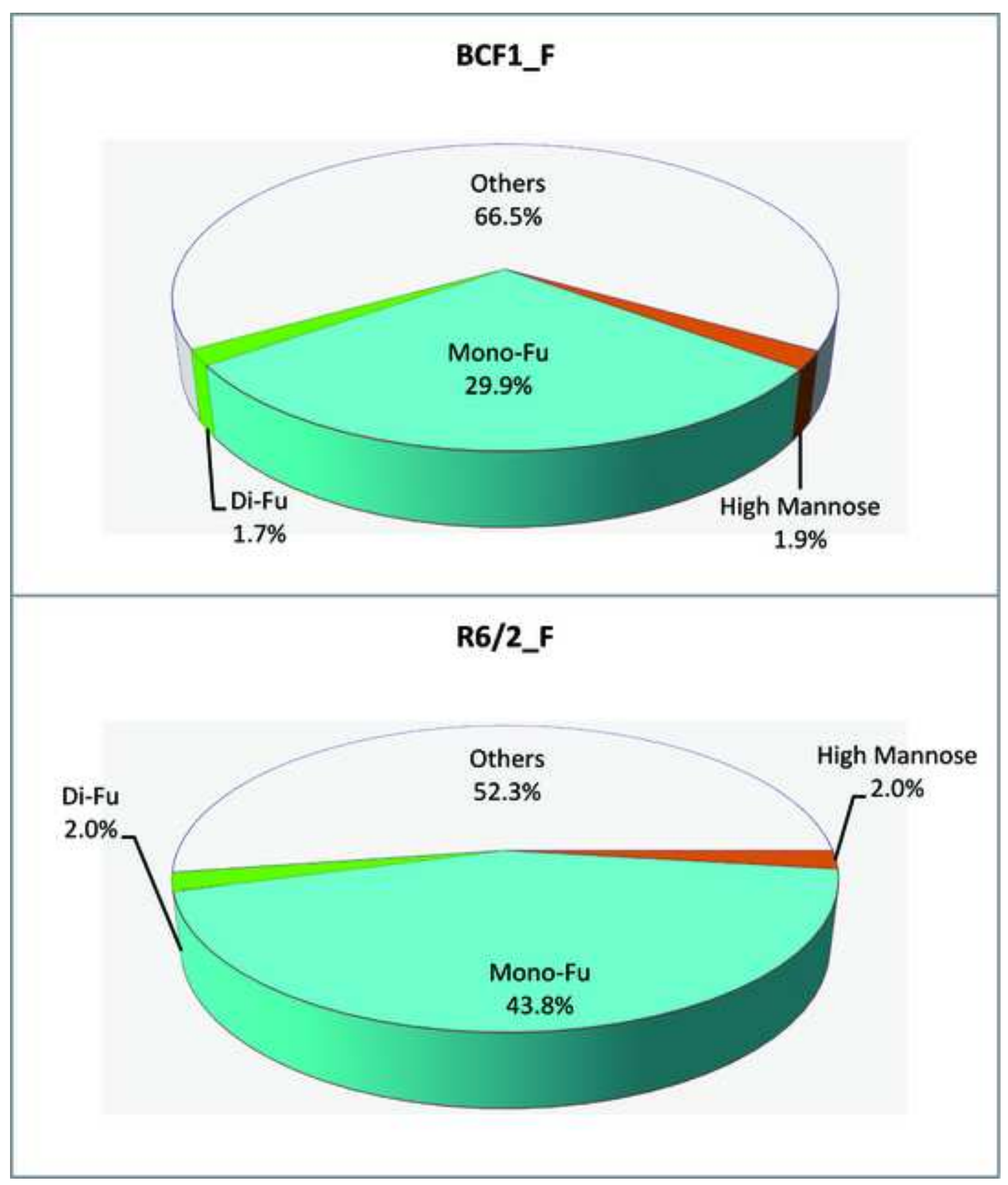

Figure 3

R6/2_F

BCF1_F 


\section{BCF1_M}

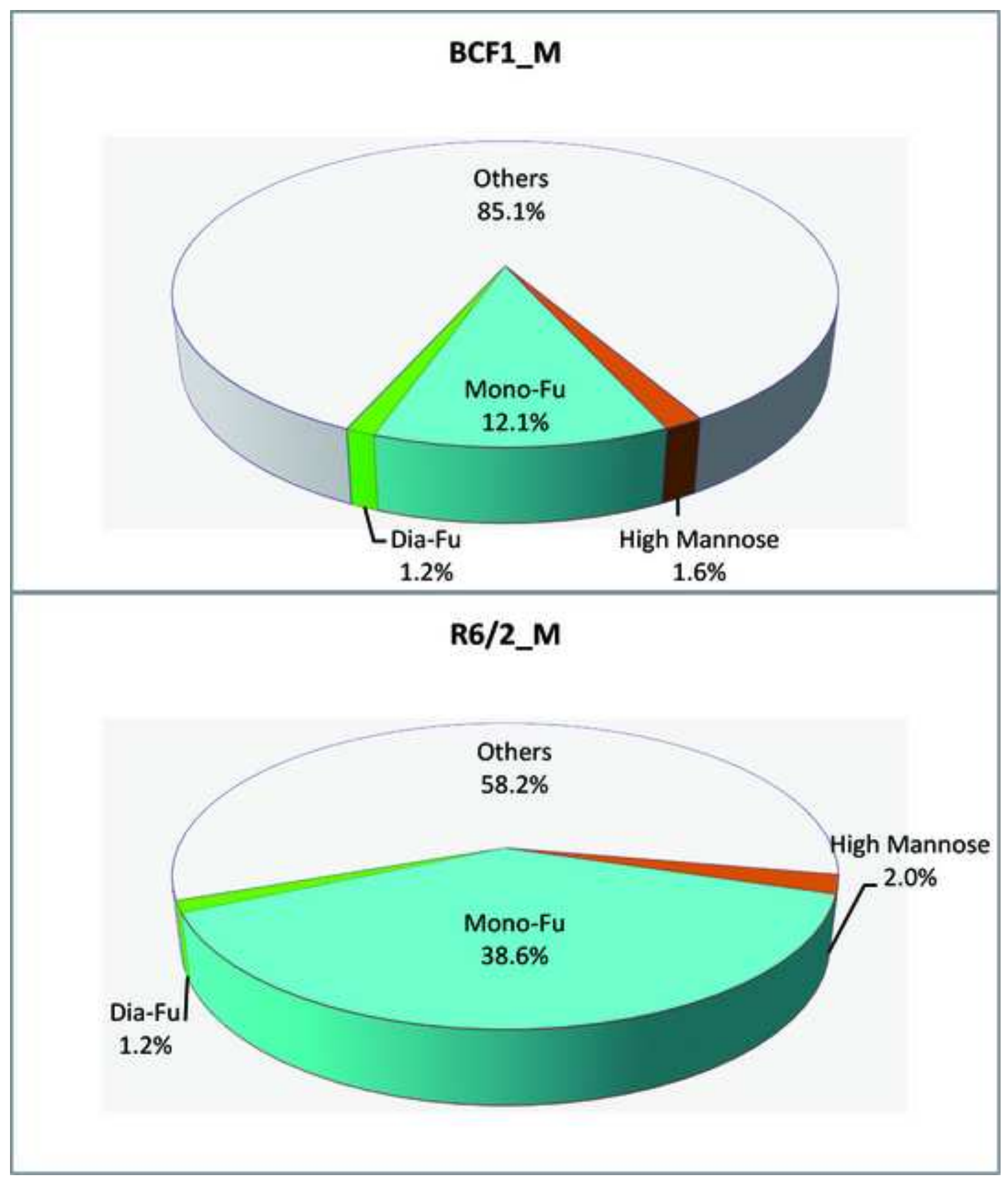

R6/2_M

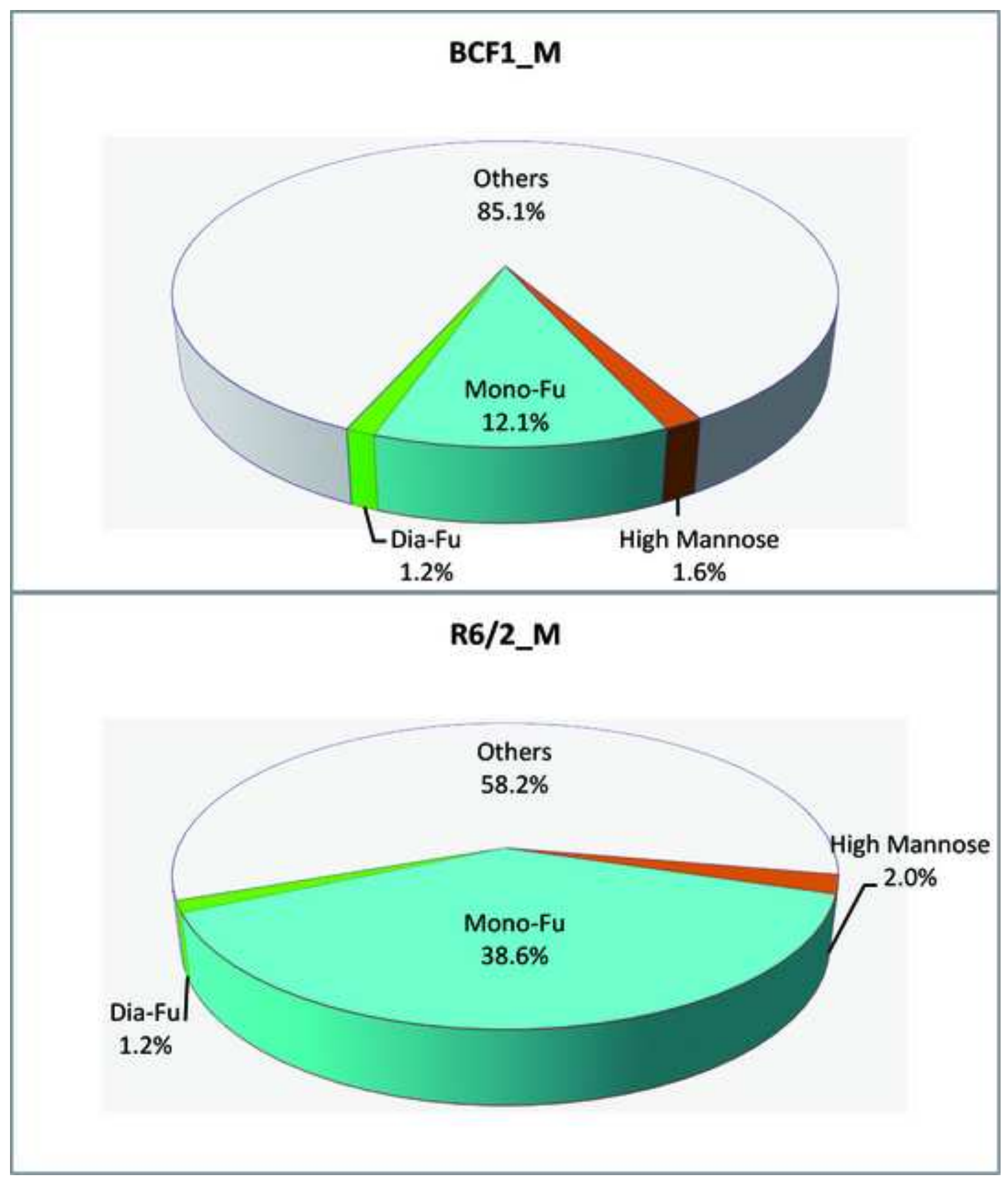

\section{R6/}

Others

$58.2 \%$ 


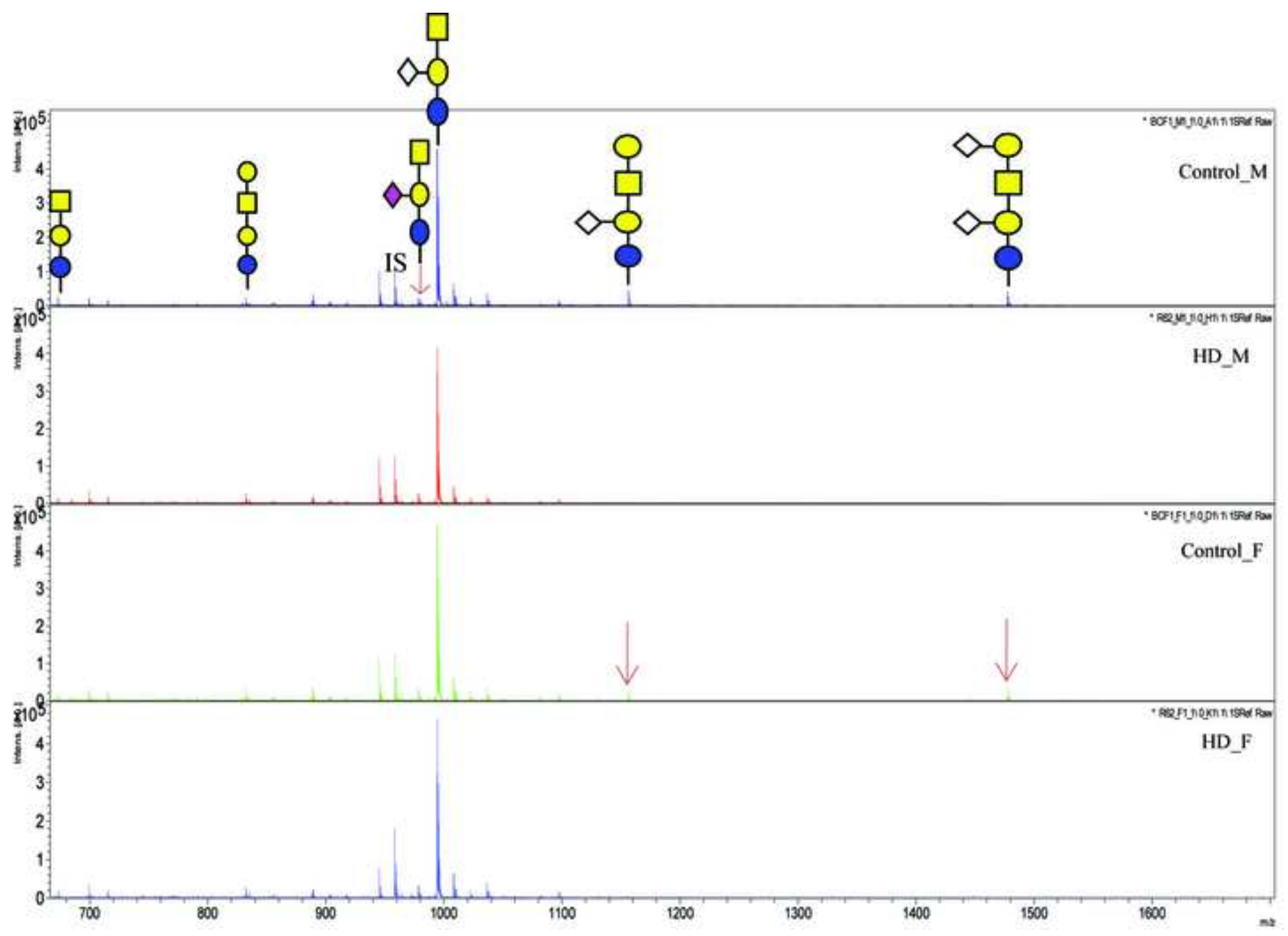


$N$-glycans Striatum vs Cortex

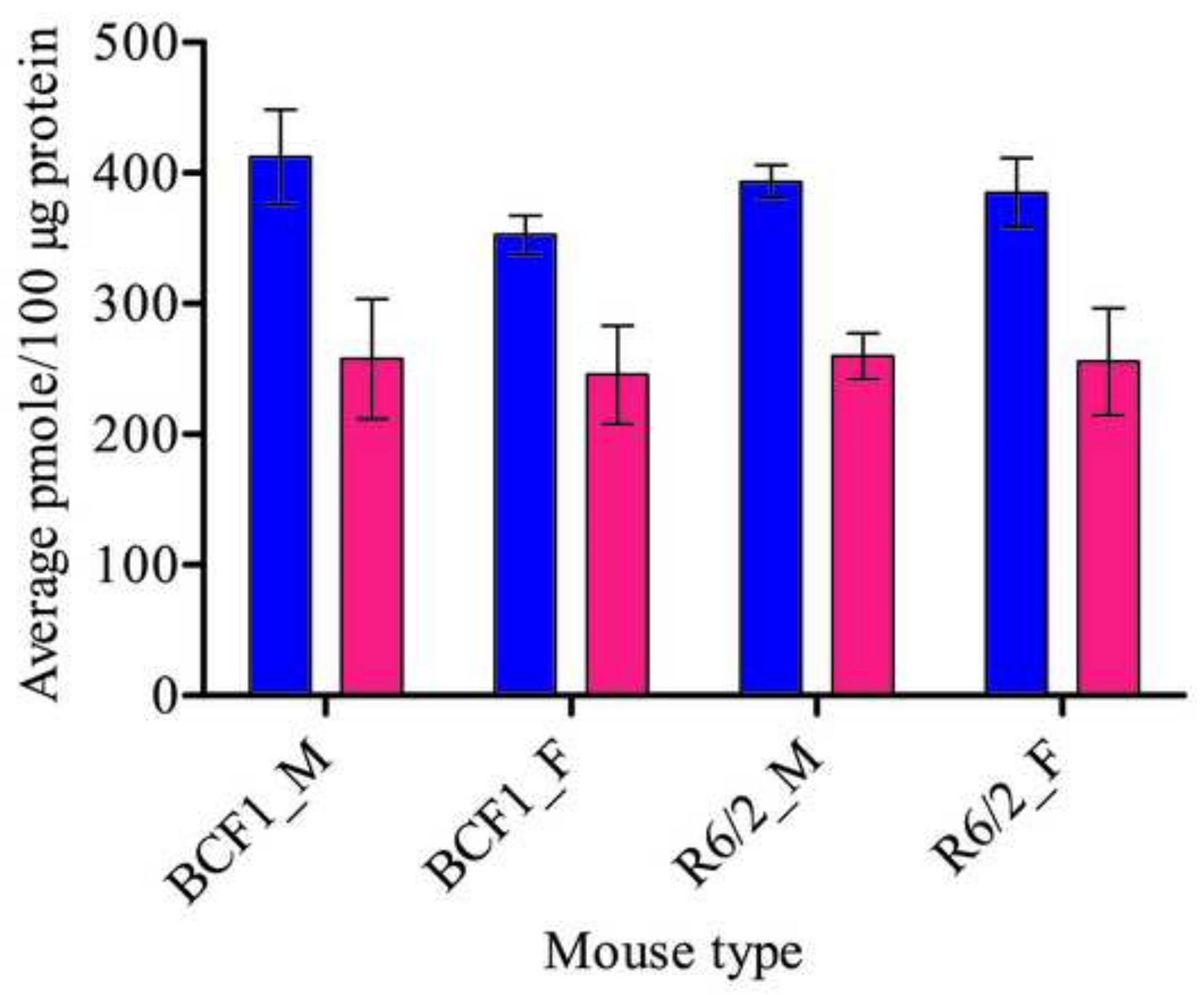




\section{O_glycans Striatum vs Cortex}

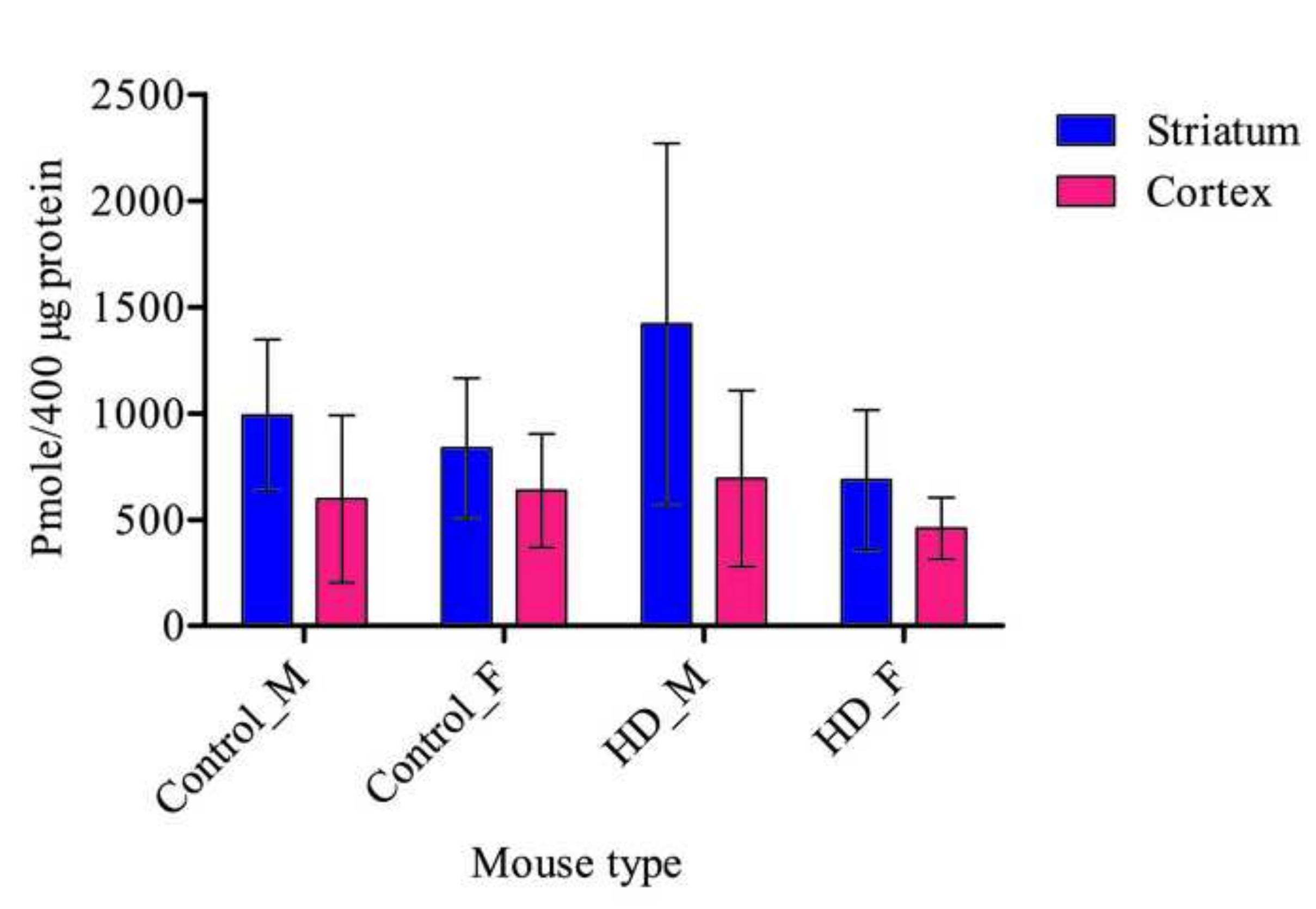

$\square$ Striatum

$\square$ Cortex 
GSLs_Stristum vs Cortex

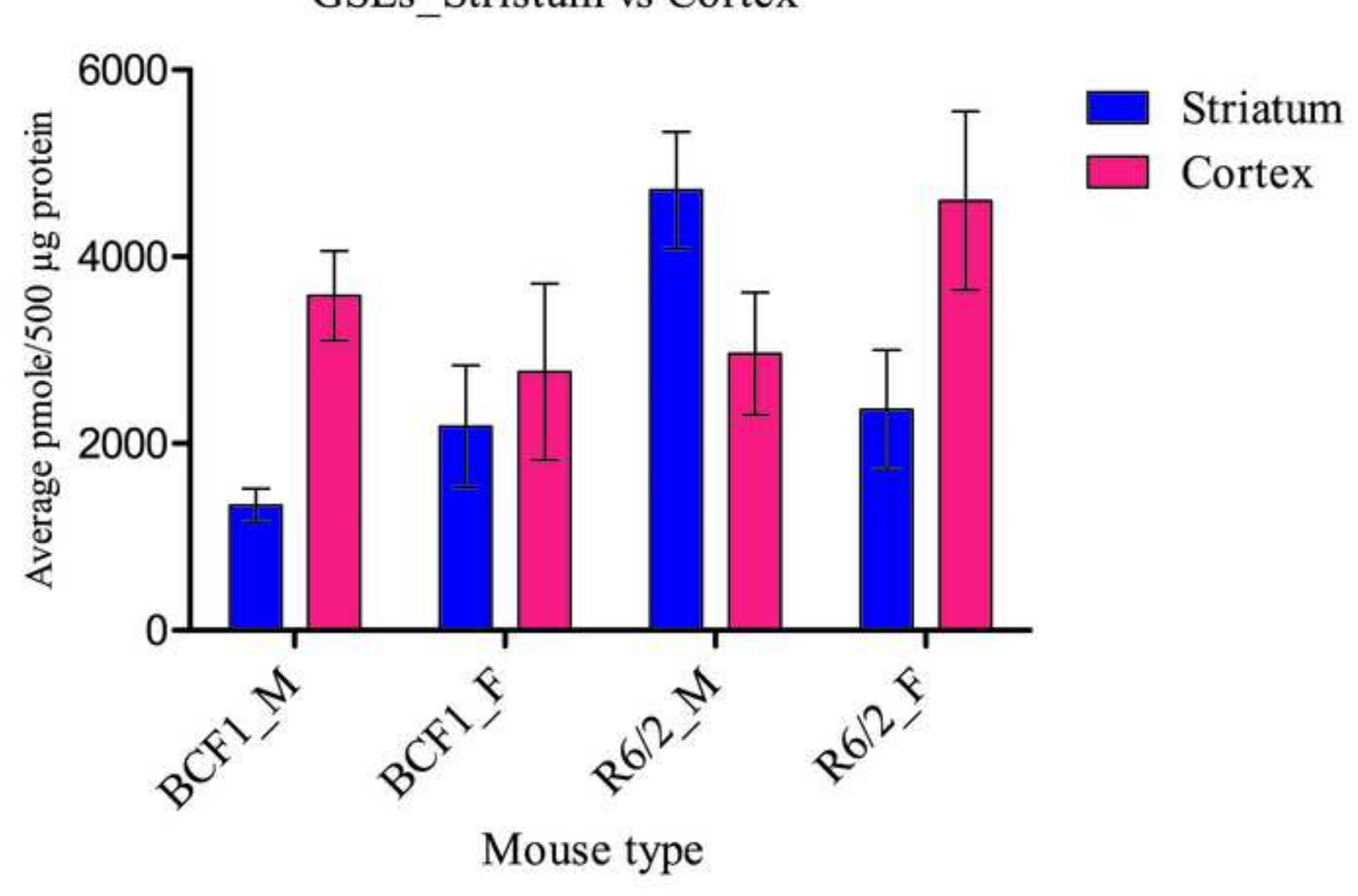

- Striatum

$\square$ Cortex 


\section{Graphical abstract}

\section{A comprehensive glycome profiling of Huntington's disease transgenic mice}

Solomon T. Gizaw ${ }^{\mathrm{a}}$, Toshiaki Koda ${ }^{\mathrm{b}}$, Maho Amano ${ }^{\mathrm{a}}$, Keiko Kamimura ${ }^{\mathrm{b}}$, Tetsu Ohashi ${ }^{\mathrm{a}, \mathrm{c}}$, Hiroshi Hinou ${ }^{\text {a, c }}$,Shin-Ichiro Nishimura ${ }^{\mathrm{a}, \mathrm{c}, *}$

${ }^{[a]}$ Field of Drug Discovery Research, Faculty of Advanced Life Science, and Graduate School of Life Science, Hokkaido University, N21 W11, Sapporo, 001-0021, Japan

${ }^{[\mathrm{b}]}$ Laboratory of Embryonic and Genetic Engineering, Faculty of Advanced Life Science,Hokkaido University, N21 W11, Sapporo 001-0021, Japan

${ }^{[c]}$ Medicinal Chemistry Pharmaceuticals, Co.Ltd, N21 W12, Sapporo 001-0021, Japan
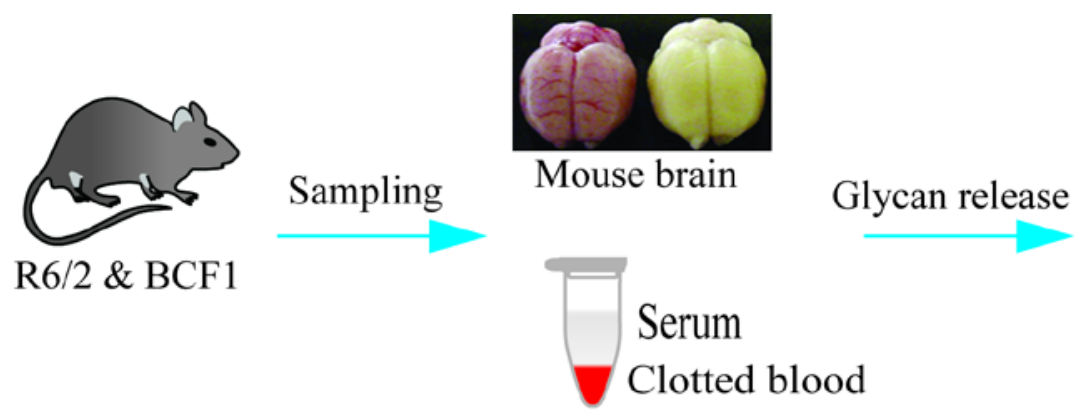

$\mathrm{R} 6 / 2$ \& $\mathrm{BCF} 1$

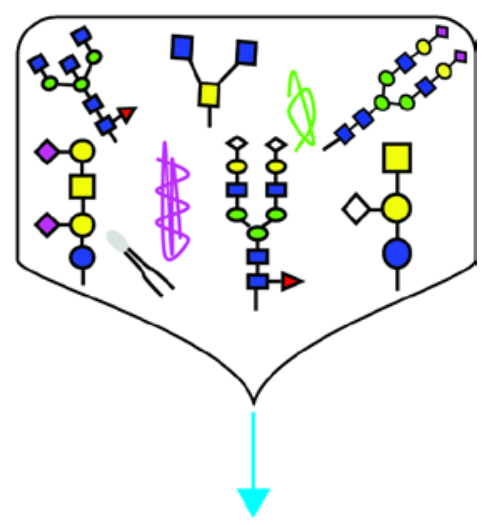

Glycoblotting MALDI-TOF/MS

Data analysis 